\title{
Stimulation Techniques of Coalbed Methane Reservoirs
}

\author{
Jicheng Zhang, ${ }^{1}$ Leilei Si $\mathbb{D},{ }^{2,3}$ Junguo Chen, ${ }^{1}$ Mehmet Kizil, ${ }^{4}$ Chunguang Wang, \\ and Zhongwei Chen (iD) ${ }^{4}$ \\ ${ }^{1}$ State Key Laboratory of Mining Disaster Prevention and Control Co-founded by Shandong Province and the Ministry of Science \\ and Technology, Shandong University of Science and Technology, Qingdao 266000, China \\ ${ }^{2}$ School of Safety Science and Engineering, Henan Polytechnic University, Jiaozuo 454003, China \\ ${ }^{3}$ State Key Laboratory Cultivation Base for Gas Geology and Gas Control, Henan Polytechnic University, Jiaozuo, \\ Henan 454003, China \\ ${ }^{4}$ School of Mechanical and Mining Engineering, The University of Queensland, St Lucia, QLD 4074, Australia
}

Correspondence should be addressed to Leilei Si; si_leilei@hpu.edu.cn and Zhongwei Chen; zhongwei.chen@uq.edu.au

Received 31 January 2020; Revised 5 June 2020; Accepted 17 June 2020; Published 10 July 2020

Academic Editor: Ondra Sracek

Copyright (C) 2020 Jicheng Zhang et al. This is an open access article distributed under the Creative Commons Attribution License, which permits unrestricted use, distribution, and reproduction in any medium, provided the original work is properly cited.

\begin{abstract}
Coalbed methane (CBM) plays an important role in securing world energy supply and transiting electricity generation from fossil fuel to renewables. CBM reservoirs are generally very tight and require effective stimulation to achieve economic extraction. In recent years, an increasing number of coal seam stimulation techniques were developed, but selecting the most suitable stimulation technique for a particular CBM reservoir condition is becoming increasingly challenging. Therefore, it is deemed very important to compare the effectiveness of different stimulation techniques in a meaningful way to guide future research directions in this area. In this paper, the stimulation techniques were firstly classified into different categories according to the stimulation mechanisms. Then, the associated principles, the history of advances, and challenges of different stimulation techniques were comprehensively reviewed. Two indexes were proposed to compare the stimulation effectiveness at the laboratory and field scales, respectively. Finally, the comparison and evaluation of each stimulation technique in respect to the stimulation effectiveness, influence range, duration, and environment were conducted in detail; the cryogenic liquid nitrogen stimulation technique receives the highest total score among the discussed laboratory-scale stimulation techniques. Hydraulic fracturing and gas injection stimulation techniques gain the highest total score among key field-scale stimulation techniques. Considering the time required for each stimulation method to take effect, high-voltage electric fracturing may have a greater potential in the future. This work is expected to help better select the optimal stimulation technique for reservoir specific conditions.
\end{abstract}

\section{Introduction}

Natural gas, as a kind of clean fuel, currently accounts for more than $20 \%$ of the world's energy consumption. In 2018 , the demand for natural gas jumped by $4.6 \%$, accounting for nearly half of the overall demand growth [1]. Figure 1 illustrates the natural gas consumption growth for some countries and regions in 2018-2024 by International Energy Agency (IEA) [1]. It clearly shows that the global demand for natural gas has been increasing over several years, especially in China. However, as the demand for natural gas rises and the conventional gas reserves drop year by year, the unconventional gas reservoirs are becoming increasingly important for fulfilling the gap and securing the world energy supply. Therefore, unconventional gas is becoming more and more important for world energy security.

Coalbed methane (CBM) or Coal Seam Gas (CSG) is an important component of unconventional gas sources, especially in areas with abundant coal reservoirs [2]. Coal media possesses a complicated matrix-fracture system. The micropores in coal matrixes provide a large amount of specific surface area so that gas can be adsorbed and stored on pore surfaces. However, the existence of the surface free energy of coal leads to the gas cannot completely be extracted, and consequently, the actual recovery rate is generally less than $50 \%$ without stimulation $[3,4]$. As shown in Figure 2, the 


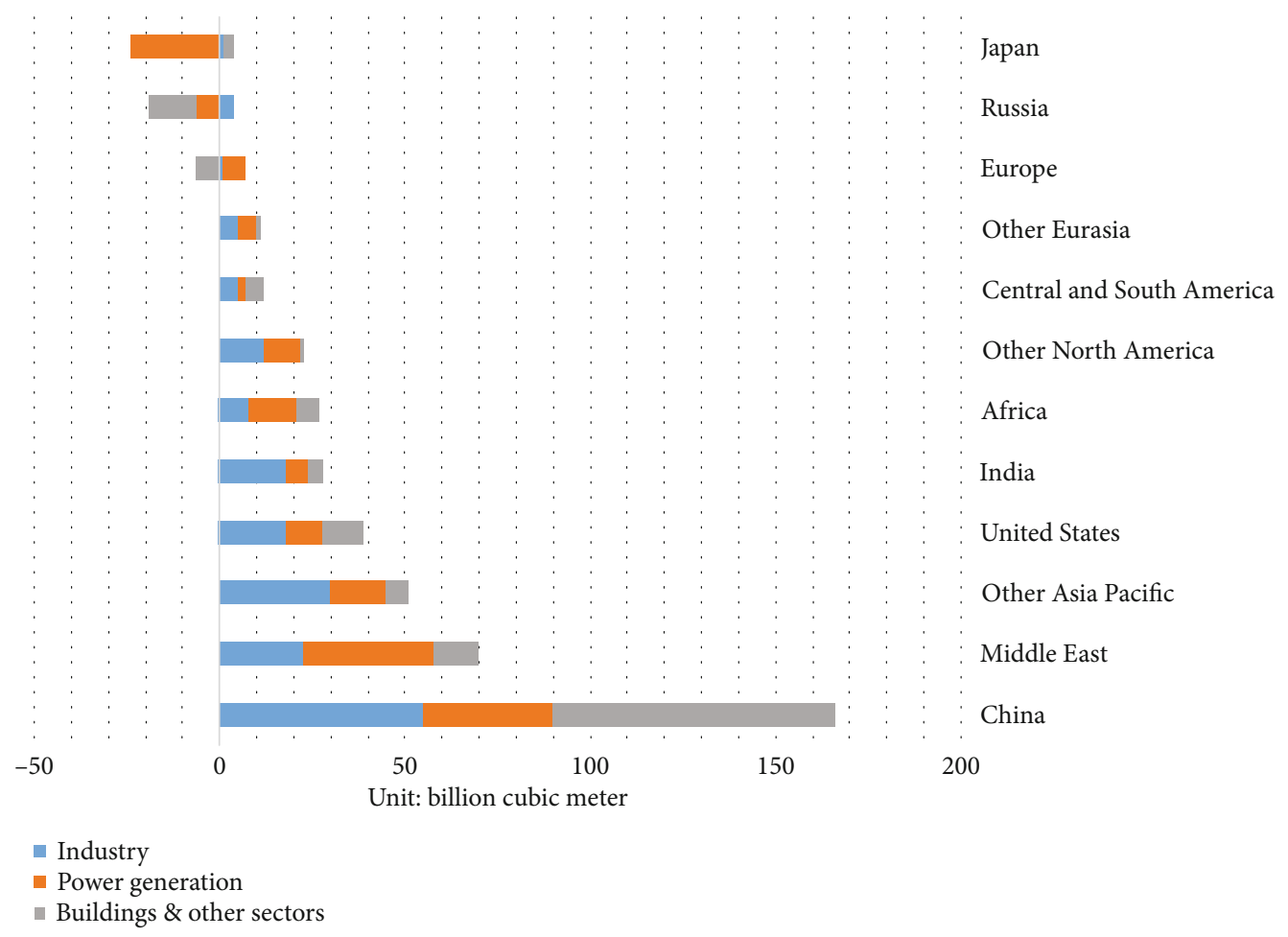

FIGURE 1: World natural gas consumption growth for selected countries and regions, 2018-2024.

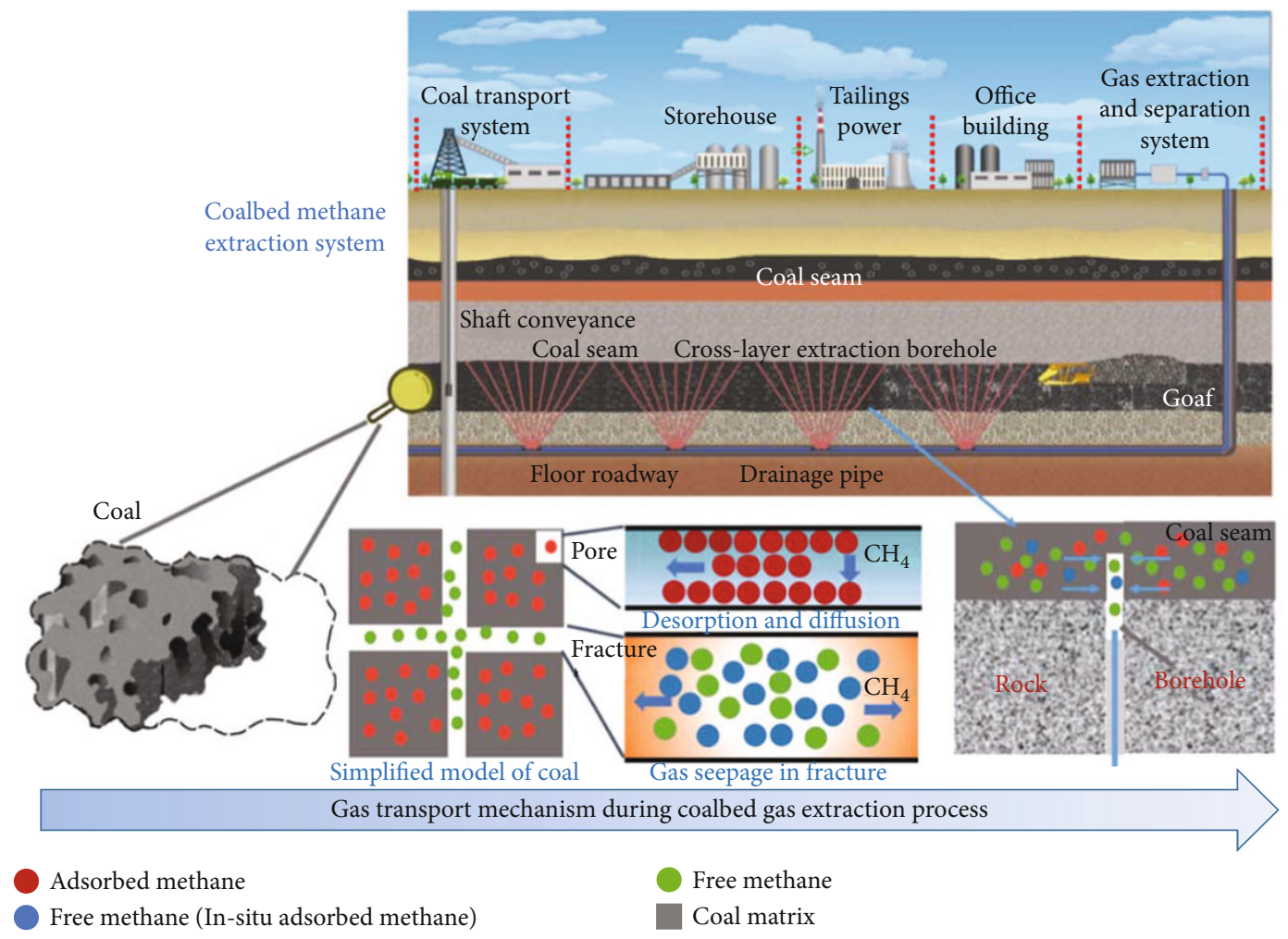

FIGURE 2: Gas transport mechanism during coalbed gas extraction process [11].

fractures in coal provide the seepage channel for gas flow. For the CBM extraction, the gas flow in the fracture is controlled by the coal fracture permeability, which plays a significant role in gas recovery [5-10]. However, most of the coal seams belong to the low-permeability reservoirs, where gas cannot be produced economically without reservoir stimulation. 


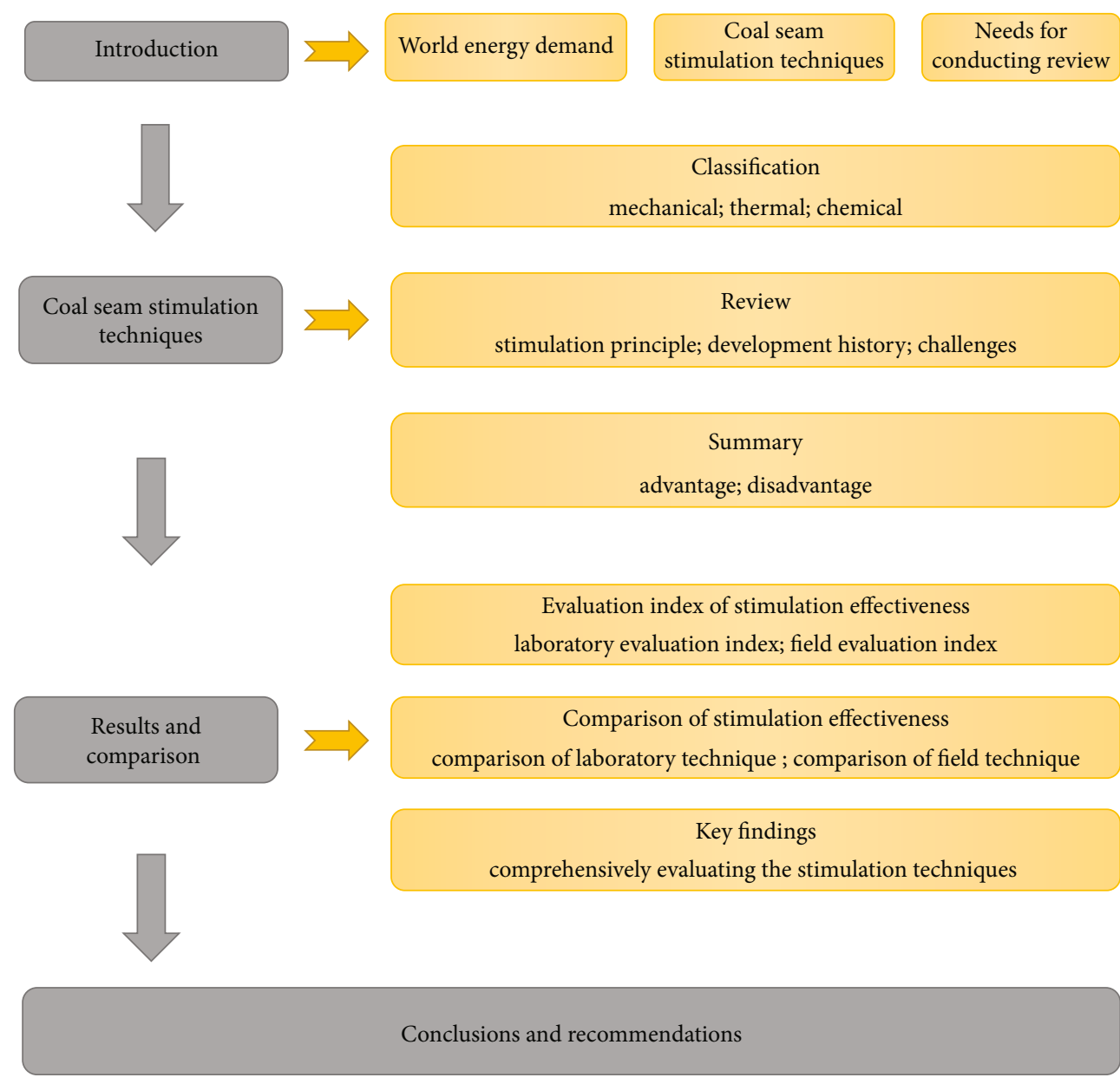

Figure 3: Organization of the paper.

Over the last several decades, a series of stimulation techniques were developed to enhance tight oil and gas reservoir, including enhanced coalbed methane (ECBM) recovery [12]. The hydraulic techniques, such as hydraulic fracturing, hydraulic slotting, and hydraulic punching, are probably the most widely used in the ECBM, which fractures coal body and creates new cracks to improve fluid flow in the seam [1315]. However, hydraulic techniques use a significant amount of water, which can potentially cause a negative impact on our environment, in terms of both the usage of fresh water and possible groundwater contamination $[16,17]$.

Some waterless stimulation techniques were later proposed to overcome the drawbacks by the hydraulic techniques, such as $\mathrm{CO}_{2}$-ECBM and $\mathrm{N}_{2}$-ECBM, which reduce the partial pressure of methane in micropores to make its desorption easier [18]. For the $\mathrm{CO}_{2}$-ECBM, it not only enhances gas recovery but also brings additional benefit to the environment via storing $\mathrm{CO}_{2}$ underground permanently.

In addition, researchers also proposed some potential stimulation methods to improve gas production, such as cryogenic liquid nitrogen, microwave heating, and highvoltage electrical stimulation techniques [19-21]. These methods have all showed a positive effect from laboratory experiments. However, few field applications were carried out due to the technical limitation implementing these techniques. The underground coal mine methane (CMM) extraction is also an important part of natural gas exploration [22]. The CMM extraction has dual benefits: reduce gas disasters and utilize the methane gas as an energy resource.

As described above, more than ten different stimulation techniques have been proposed. The previous work primarily focuses on the stimulation effectiveness of a single method, but it gets increasingly challenging to compare the effectiveness of different stimulation techniques and to choose the best available stimulation technique for a particular coal seam reservoir. Therefore, it is important and useful to review and compare all existing key CBM reservoir stimulation methods.

The remainder of the paper is organized as follows. The stimulation techniques are firstly classified based on the stimulation mechanism. Next, the stimulation techniques are reviewed and the relative merits of stimulation techniques are analyzed. Then, numerous data from previous studies are collected and an evaluation index is proposed to compare the effectiveness of stimulation techniques. Finally, the stimulation techniques are comprehensively evaluated according to the effectiveness, influence range, duration, and environment. The detailed structure is illustrated in Figure 3. 


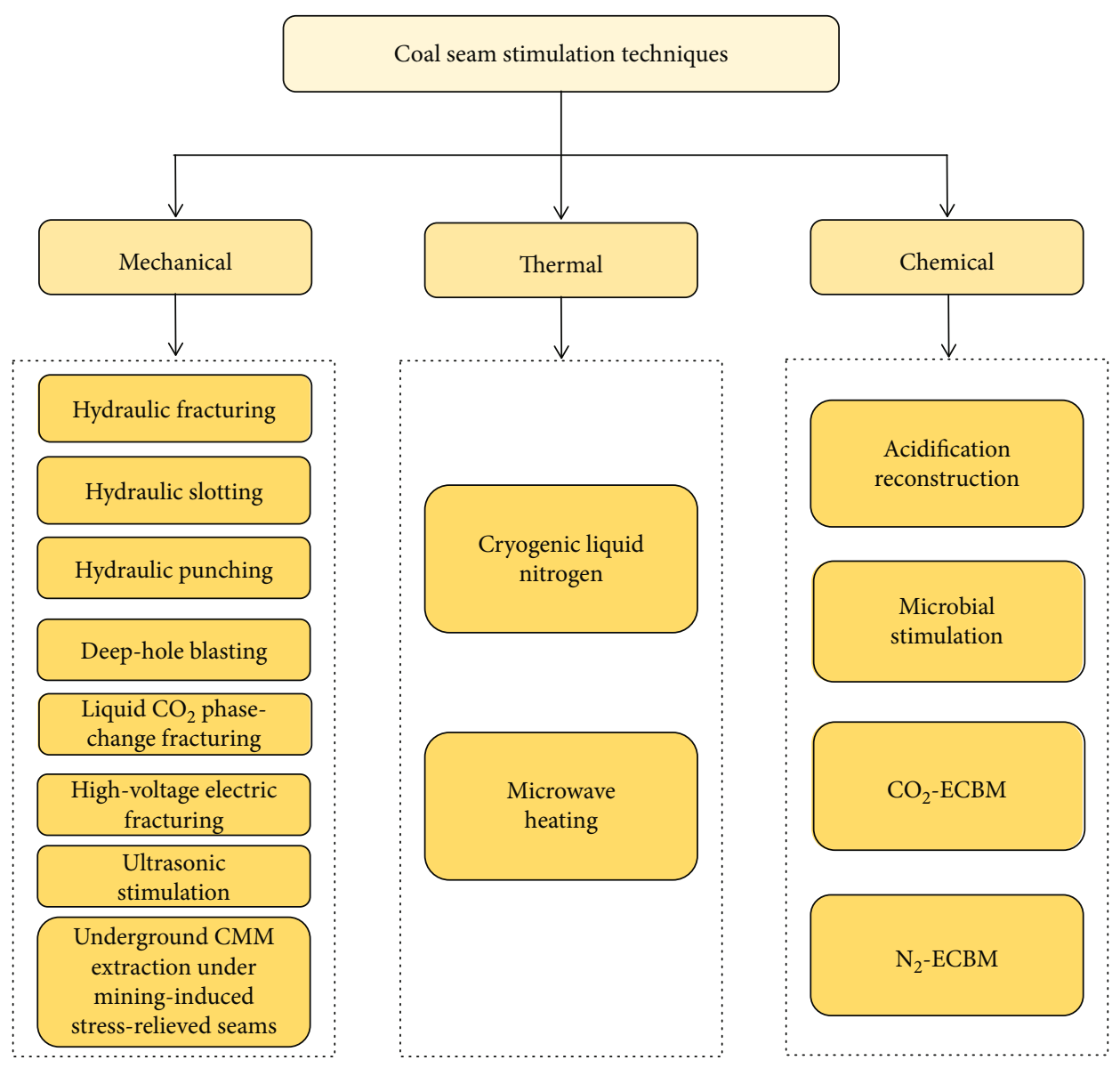

Figure 4: Classification of coal seam stimulation techniques.

\section{Coal Seam Stimulation Techniques}

2.1. Classification of Coal Seam Stimulation Techniques. In this paper, the stimulation techniques were classified into three groups according to the stimulation mechanism. First is the mechanical stimulation technique, such as the hydraulic technique and deep-hole blasting, which causes the redistribution of field stresses and creates new cracks by applying external excessive forces to the coal seam. Second is the thermal stimulation technique, such as the cryogenic liquid nitrogen and microwave heating techniques, which fragmentate coal body integrity and reduce coal mechanical strength due to associated temperature effect, leading to improved permeability. The third is the chemical stimulation technique, such as acidification reconstruction and microbial stimulation technique, which can alter the porosity by dissolving the minerals or organic matters in coal and thus improve the permeability. It is noted that the gas injection is classified as chemical stimulation techniques because its mechanism is to displace methane gas due to the difference in gas adsorption affinity to coal. The details of the classification are shown in Figure 4.

\subsection{Mechanical Stimulation Techniques}

2.2.1. Hydraulic Fracturing. As shown in Figure 5, hydraulic fracturing is to inject the high-pressure fluids into the coal seam.

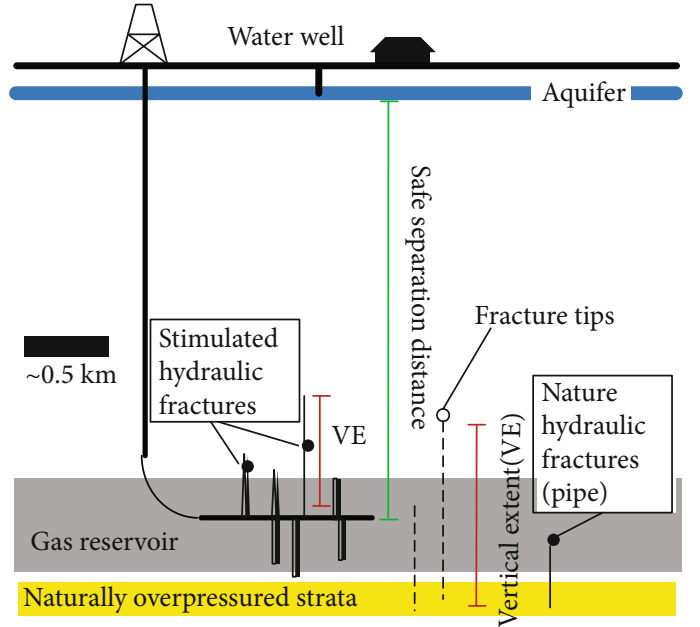

FIgURE 5: Schematic diagram showing stimulated hydraulic fractures within a shale gas reservoir [24].

Then, the fracturing fluids with proppant are pushed to enhance the primary fracture of the coal seam, causing that the coal seam permeability is improved due to the expansion of primary fracture and the creature of secondary fracture [23].

In 1947, the hydraulic fracturing was first successfully carried out in Kelpper1 well of Kansas, America [25]. 
Extensive field trials have been performed since then to investigate the influence of hydraulic fracturing on gas production and change of permeability during the past years. After the 2010s, hydraulic fracturing has made significant progress and become a common stimulation method for unconventional oil and gas explorations. Globally, unconventional natural gas resources recovered through hydraulic fracturing are expected to account for nearly half of newly developed gas production projects by 2035 [26]. Therefore, as the reservoirs depth rises, new problems and challenges gradually raise due to its stronger absorptivity, higher stress, and lower permeability. One of key challenges associated with hydraulic fracturing is that coal permeability reaches the peak right after the fracturing, but then the gas recovery efficiency drops gradually due to the time-dependent crack closure. Some improved hydraulic fracturing techniques were proposed to address it, such as the graded particle injection and the pulse hydraulic fracturing technique [27-30], which can pump the fluid into the coal seam with a certain frequency, leading to a well-distributed fracture network under pulse loading conditions, which possesses a better stimulation effect compared with the traditional hydraulic fracturing [31].

Although the hydraulic fracturing technique has been widely used in coal seam stimulation, it has some key drawbacks:

(i) The gas in micropores is hard to diffuse to the outside due to the water-block effect

(ii) The new fractures close up gradually over time, leading to a decline in gas production

(iii) The groundwater would be polluted due to the chemical substances of fracturing fluid

(iv) The use of water induces clay hydration swelling, causing formation damage, which is detrimental to reservoir performance

(v) There are an increasing number of public objections due to the possible seismicity induced by hydraulic fracturing $[32,33]$.

(vi) It may damage the coalbed top and floor due to its high pressure, leading to unfavorable gas leakage or emission

2.2.2. Hydraulic Slotting. Hydraulic slotting is using the highpressure waterjet to form the fracture network by cutting slots and breaking the coal in the existing extraction boreholes. Then, the stress of coal seam around the borehole is relieved, leading to the improvement of coal permeability. Figure 6 is the schematic diagram of underground hydraulic slotting.

Since the 1970s, a series of field experiments for hydraulic slotting was carried out in the Hebi Mining Bureau, China [35]. Field trials demonstrated that the effective extraction radius was doubled, and the amount of gas extraction was improved 1-3 times after hydraulic slotting [35]. Since the 1980s, significant progresses have been made to the hydraulic

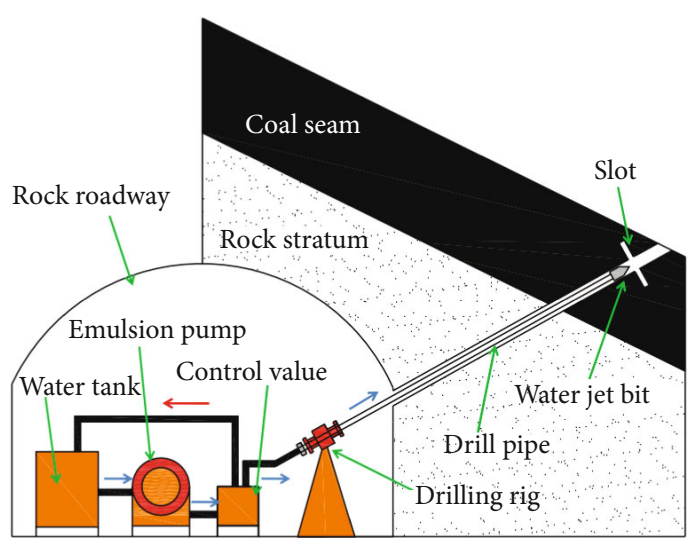

FIgURE 6: Schematic diagram of underground hydraulic slotting (Modified from [34]).

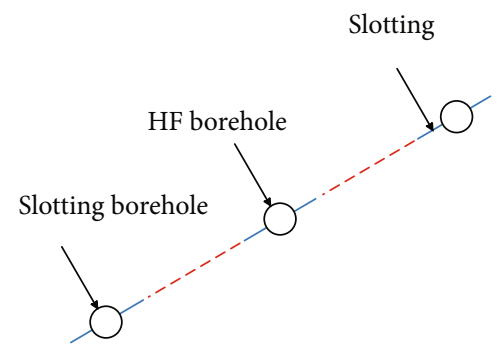

Figure 7: Combination stimulation technology of hydraulic fracturing and hydraulic slotting.

slotting, and many modified hydraulic slotting techniques were developed and successfully trialed in oil and gas industry, such as the solid-liquid waterjet, gas-liquid waterjet, self-resonating cavitating waterjet, swirling waterjet, and high-pressure pulse waterjet $[36,37]$. Furthermore, these stimulation techniques have been successfully applied in underground coal mine methane gas drainage in China [22]. All these field applications showed that the hydraulic technique is a useful active stimulation method in the low permeability coal seam. However, it is very difficult to put the cutting equipment into the predesigned location in the borehole in the soft coal seam due to the borehole collapse. Compared with the hydraulic fracturing, hydraulic slotting is easy to be implemented operation with lower cost, but its effective influence zone is significantly smaller. Therefore, some studies proposed the combination stimulation technology of hydraulic fracturing and hydraulic slotting, which is also called directional hydraulic fracturing. As shown in Figure 7, the predesigned fracture was first cut by using hydraulic slotting in the directional borehole. Then, the hydraulic fracturing technology was carried out in the fracturing borehole. The hydraulic fracture would extend along the direction of predesigned fracture [38-41]. This method is able to control the extension direction of hydraulic fracture, and thus avoiding the destroy of coalbed top or floor. In addition, it is able to improve the effective scope of hydraulic slotting.

2.2.3. Hydraulic Punching. As shown in Figure 8, hydraulic punching uses the high-pressure waterjet to break the coal around the borehole, leading to the stress relief of the coal 


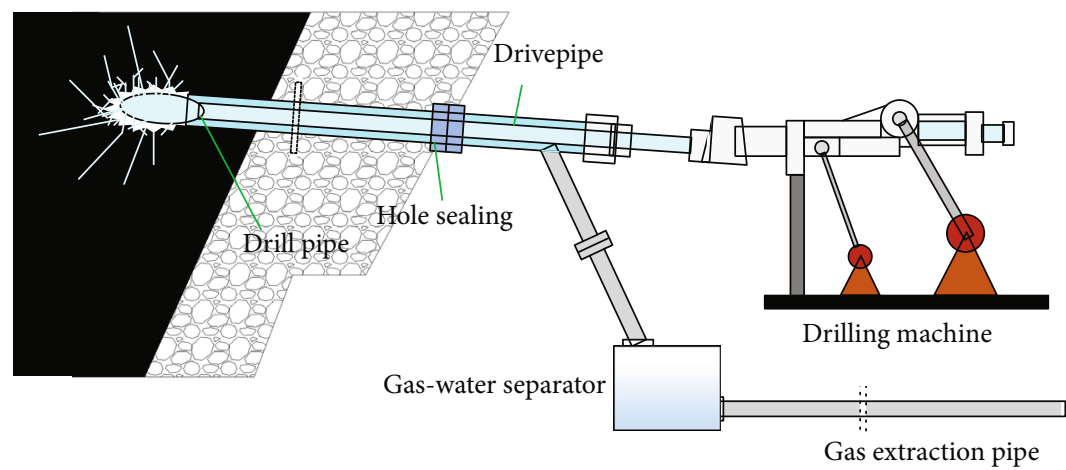

FIGURE 8: Schematic diagram of underground hydraulic punching [45].

seam, thus enhancing the permeability. It is also an effective method for preventing coal and gas outburst in coal mine because it can release the coal energy as the coal is washed out $[42,43]$. After hydraulic punching, the radius of the borehole was greatly increased so that the relief scope of hydraulic punching is greater than the common borehole [44]. The hydraulic punching was primarily used in the excavation of coal roadways, rock cross-cut coal uncovering, and crossstrata extraction borehole.

Take China for instance, Nantong Mining bureau successfully carried out the hydraulic punching in Yutianbao coal mine in 1965, and then this technology was applied in Meitian mining bureaus, Liuzhi mining bureaus, Beipiao mining bureaus, and Jiaozuo mining bureaus [46]. More recently, some works proposed the multihydraulic stimulation technique combining the hydraulic punching and hydraulic fracturing, which can greatly improve gas production. Compared with other hydraulic techniques, hydraulic punching is more flexible and easier to operate. It is noticed that it works better for the soft coal seam, but its effectiveness on hard coal seams are not significant so far.

2.2.4. High-Voltage Electric Fracturing. High-voltage electric fracturing uses the shock wave and high temperature during discharging to break the solid materials. In the 1970s, the high-voltage electric fracturing technique was applied in the oil exploration by America and the Soviet Union. Then, in 1986, China began to apply this technique into oil field [47]. Over the past decades, as shown in Figure 9, some work proposed to use the high-voltage electric to stimulate coal seams $[48,49]$.

The high-voltage electric fracturing technique can be divided into two types: electrohydraulic fragmentation and electrical fragmentation, as shown in Figure 10. The electrohydraulic fragmentation allows the discharge electrode and coal sample surrounded by liquid. The coal sample is damaged by the shock waves generated in the liquid during discharging, leading to the enhancement in permeability. The latter relies on the direct contact between the discharge electrode and the coal seam. The coal sample is fragmented by the extensional forces generated during discharging [51, 52].

Maurel et al. [55] carried out the preliminary experiments for electrohydraulic fragmentation and thought that the extent of intrinsic permeability enhancement using the

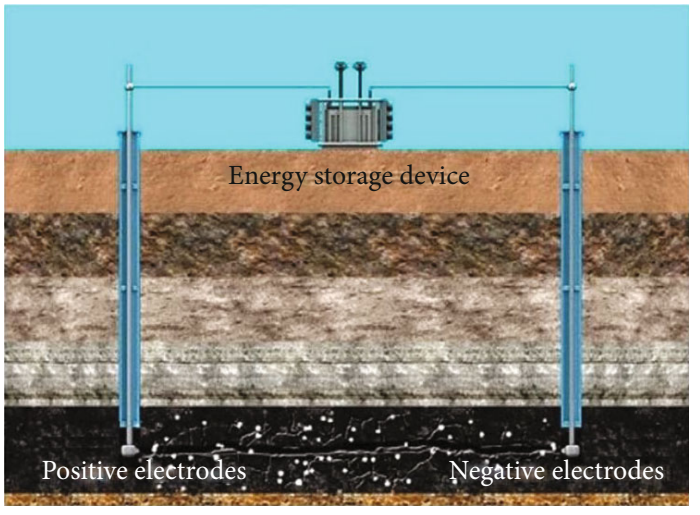

FIgURE 9: Schematic diagram of coal seam stimulation by using high-voltage electric fracturing [50].

electrohydraulic fragmentation would depend on the intensity of injected energy and the number of shocks. Some studies further investigated the influence of stress on the electrohydraulic fragmentation [56]. However, these work primarily focused on the analysis of enhanced mortar properties by electrohydraulic fragmentation. Therefore, Ren et al. [54] used the electrohydraulic fragmentation to improve the coal permeability and found that the porosity of coal increased from $8.12 \%$ to $14.71 \%$, indicating that the electrohydraulic fragmentation technique is a possible coal seam stimulation technique.

However, as shown in Figure 10, the damage mechanism of two kinds of high-voltage electric fracturing is different. The coal is broken by compressional forces for electrohydraulic fragmentation, while the failure is largely due to tensile forces for electrical fragmentation. The energy required for electrical fragmentation is far less than that for electrohydraulic fragmentation because the tensional strength of coal is usually only $4 \%-5 \%$ of its compressional strength [57, 58]. Nevertheless, the voltage at which the coal sample is fragmented is still very great, which may cause safety problems during discharging [59]. Some research investigated the influence of electrical fragmentation on the coal properties $[53,60]$. Some works investigated the breakdown voltage of coal samples saturated with $\mathrm{NaCl}$ solution by using the electrical fragmentation method and found that the breakdown voltage obviously decreases $[21,61]$. In China, the 

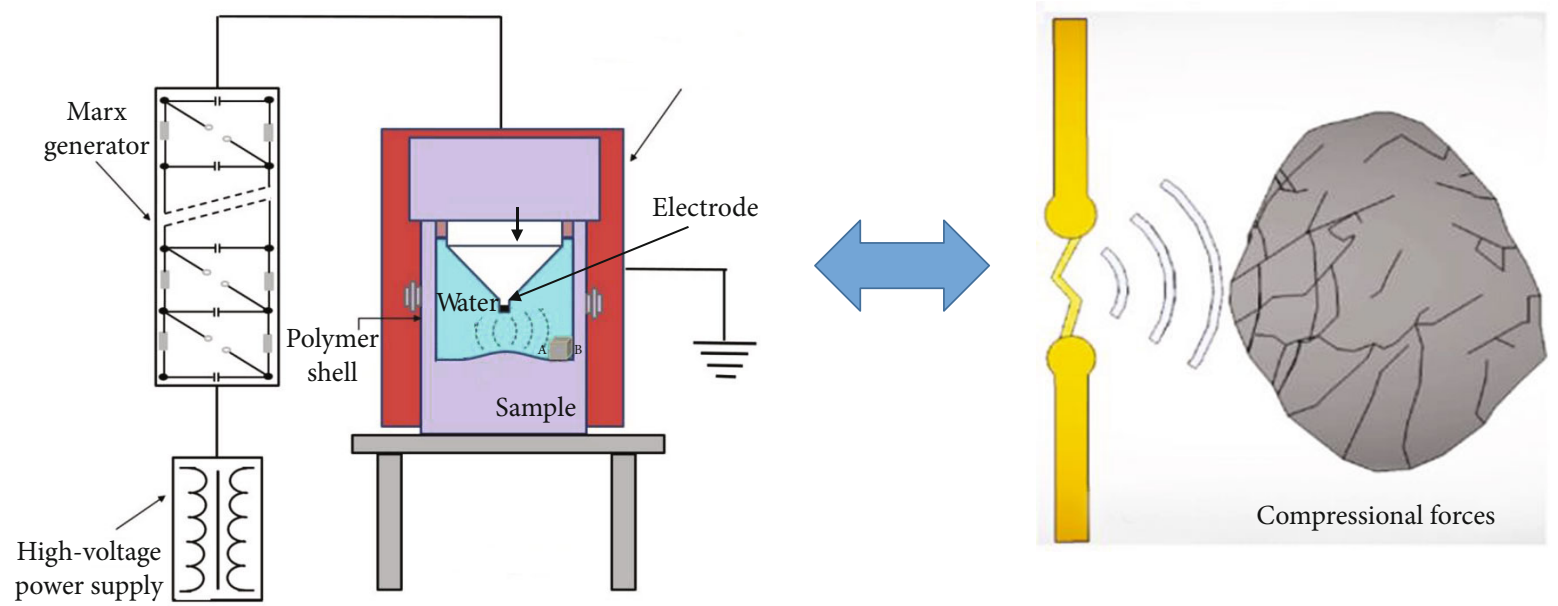

(a) Electrohydraulic fragmentation
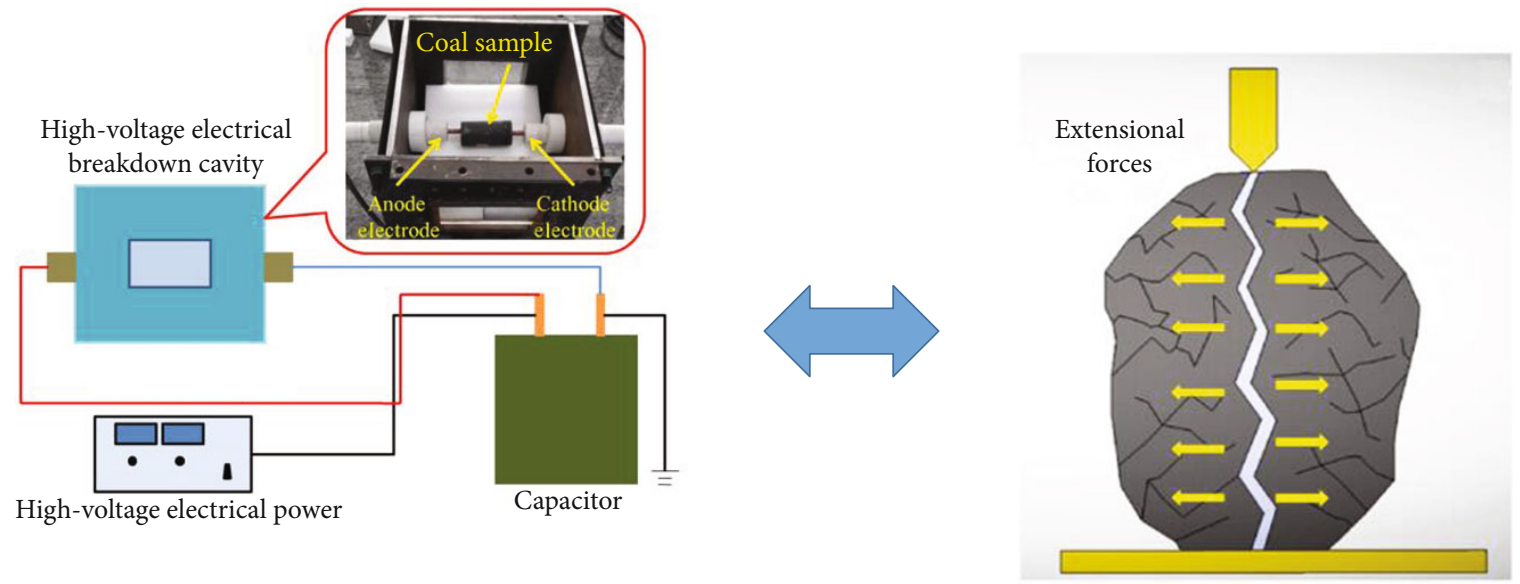

(b) Electrical fragmentation

FIGURE 10: Schematic diagram of two kinds of high-voltage electric fracturing and their principles [53, 54].

high-voltage electric fracturing has been used in approximately $30 \mathrm{CBM}$ wells with ultra-low permeability. However, the improvement of gas production does not seem significant.

In summary, there are numerous further studies to be done before it can be widely applied to the fields:

(i) The influence zone is small

(ii) The direction of fracture cannot be controlled

(iii) It is hard to be applied into the underground due to be lack of the corresponding explosion-proof device

2.2.5. Deep-Hole Blasting. Deep-hole blasting technique is to use the dynamite to act the coal around a borehole, leading to the improvement in permeability due to the damage of coal mass and the stress relief around the borehole. The deephole blasting technique can be classified into three kinds: deep-hole presplit controlling blasting, deep-hole loose blasting, and energy-accumulated hydraulic blasting [62]. As shown in Figure 11, the influence zones of deep-hole blasting were divided into three parts: crushed zone, fractured zone

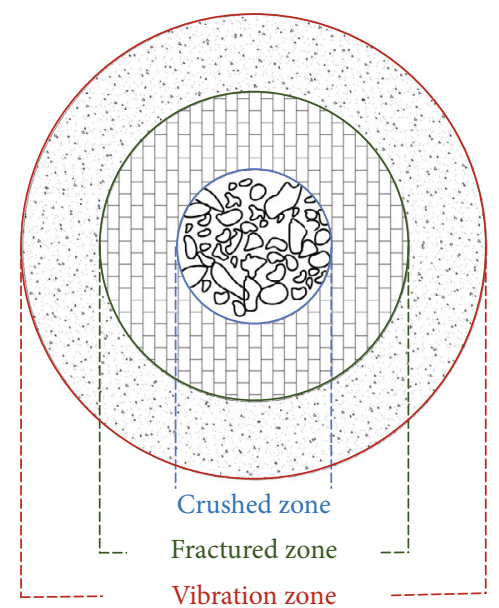

FIGURE 11: Influencing zones of deep-hole blasting [63].

with radial and annulus fractures, and vibration zone. The gas permeability in the crushed zone and fractured zone can be greatly improved. 


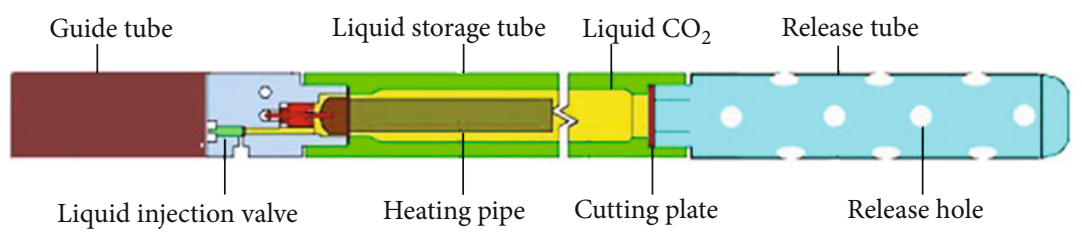

FIgURE 12: Schematic diagram of liquid $\mathrm{CO}_{2}$ phase-change fracturing system [64].

Since the 1960s, the deep-hole loose blasting stimulation technique has been widely used in mine gas extraction in China [63]. However, the crushed zone and fractured zone of the deep-hole loose blasting stimulation technique is relatively small, and the fracture direction cannot be controlled. Therefore, some work proposed the energy-accumulated hydraulic blasting active stimulation, which can release energy along the extension direction of the energyaccumulating slot, and thus control the fracture direction. In addition, this method can extend the fractured zone due to the concentration of blasting energy, thereby enhancing gas production.

The key challenges associated with deep-hole blasting are the following: First, the deep-hole blasting active stimulation technique cannot be used in coal seam with high gas content because it may induce gas disasters. Second, it may cause damage for the roof and floor of the coal seam, bringing water flow into coal seams. Third, it is difficult to construct a deep enough borehole due to borehole collapse particularly in soft coal seams.

2.2.6. Liquid $\mathrm{CO}_{2}$ Phase-Change Fracturing. The liquid $\mathrm{CO}_{2}$ phase-change fracturing technique is to use the enormous energy generated by the phase transformation of $\mathrm{CO}_{2}$ to break coal seams. The mechanisms of $\mathrm{CO}_{2}$ fracturing are illustrated in Figure 12 [64]. $\mathrm{CO}_{2}$ is stored in a storage tube. By heating the special chemicals in a very short time, the liquid $\mathrm{CO}_{2}$ would turn into a gas state, causing the volume of $\mathrm{CO}_{2} \mathrm{dra}-$ matically expand by approximately 600 times. Once the pressure in liquid storage tube exceeds the limit of cutting plate, the cutting plate is broken and high-pressure carbon dioxide enters the release tube and acts on the coal body, resulting in the new fracture and thus the improvement in permeability.

In the 1960s, the liquid $\mathrm{CO}_{2}$ phase-change blasting technique was carried out in tunnel excavation [65]. Then, Cardox International Limited in the UK further improved and designed the liquid $\mathrm{CO}_{2}$ blasting system. After that, the liquid $\mathrm{CO}_{2}$ blasting system was called the Cardox system. In China, the liquid $\mathrm{CO}_{2}$ phase-change fracturing technique has been used in many mines to enhance the gas permeability, such as Shanxi Province, Henan Province, and Guizhou Province [64, 66, 67]. The results showed that gas production increased to 2-5 times after using liquid $\mathrm{CO}_{2}$ phase-change fracturing. Compared with the traditional blasting technique with dynamite, the liquid $\mathrm{CO}_{2}$ phase-change blasting possesses a lower risk as it is spark-free when it is used underground. In addition to fracturing, the $\mathrm{CO}_{2}$ could promote methane desorption due to the strong adsorption capacity.

However, it has three main disadvantages: (i) The crack extension is hard to be controlled

(ii) The excessively pulverized coal powder may cause pores blockage

(iii) The filling process of liquid $\mathrm{CO} 2$ is with a certain of security risk

2.2.7. Underground CMM Extraction under Mining-Induced Stress-Relieved Seams. The CMM extraction under the mining-induced stress relief zone is regarded as the best technology to extract CMM from extremely low permeability and outburst prone coal seams in China [68]. This technique only applies to multiple coal seam condition. In this technique, the coal seam with low gas content and without outburst risk is chosen as the first coal seam to be mined. As shown in Figure 13, the rock mass moved to the gob after the first coal seam was mined. Then, it formed three zones above the mining coal seam: caving zone, fractures zone, and bending zone, as well as two zones under the mining coal seam: floor heave fractures zone and floor heave deformation zone. The gas permeability of protected coal seam is greatly improved due to the coal seam deformation and stress relief.

In 1958, the CMM extraction under mining-induced stress relief is carried out in Beipiao and Chongqing coal mine areas and achieved great results in gas control and prevention. In 1996, Qian et al. [69] firstly proposed the key stratum in ground control theory, which provided the theory guidance for fracture evolution during mining. In 2003, Cheng et al. [70] proposed the extraction method for longdistance stress-relief coal seam by combining numerical simulation with a field test. Until now, the CMM extraction method under mining-induced stress is still the most effective method for extracting CMM for low permeability coal seams in China.

\subsection{Thermal Stimulation Techniques}

2.3.1. Cryogenic Liquid Nitrogen Stimulation Technique. It is generally believed that conventional hydraulic stimulation techniques consume a tremendous amount of water and can pollute of groundwater reservoirs [71]. Therefore, the cryogenic liquid nitrogen stimulation technique has attracted much attention by researchers. Figure 14 is the schematic diagram for the coal seam after cryogenic liquid nitrogen stimulation. It is generally believed that there are lots of water in the cleat of the original coal seam, and when water turns into ice at low temperature the volume would increase by $9.1 \%$, and thus the phase change could theoretically generate $270 \mathrm{MPa}$ of expansion pressure. Based on the phase 


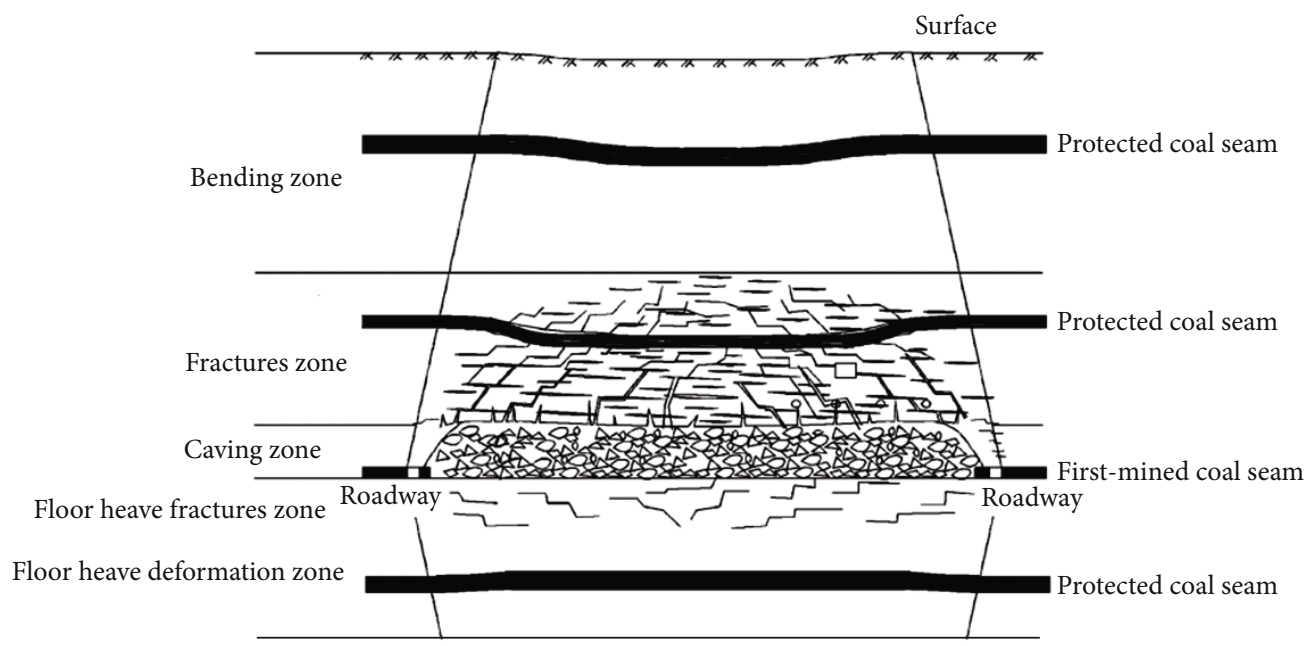

FIGURE 13: Deformation and fracture of protected coal seams in the process of mining protection coal seams [68].
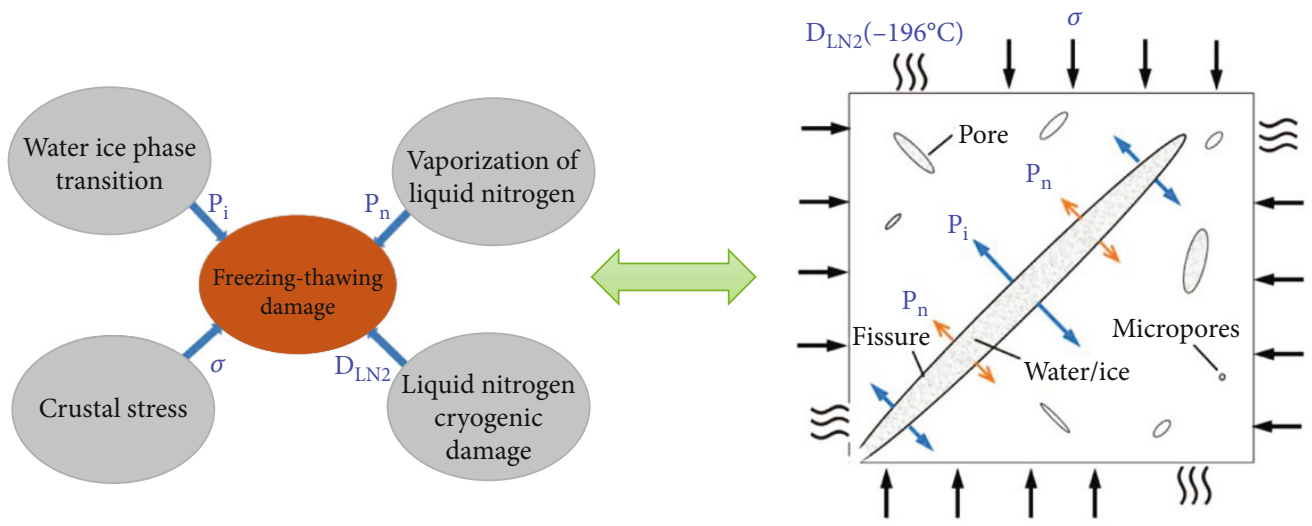

FIGURE 14: Schematic diagram for the coal seam after cryogenic liquid nitrogen stimulation [72].

transition of water, the liquid nitrogen technique is to inject the cryogenic liquid nitrogen into the coal seam to fracture coal medium and thus improve the coal permeability. In addition, the liquid nitrogen gasification and lowtemperature effect can damage the coal and create the fracture so that the coal seam permeability increases.

Table 1 is the focused areas of different studies. In the 1990s, McDaniel et al. $[19,73]$ carried out the field applications of liquid nitrogen as a stimulation liquid in the San Juan basin, New Mexico, USA, indicating that the liquid nitrogen is able to increase the gas permeability. In recent years, more and more works investigated the influence of cryogenic gas on the coal pores, mechanical properties, energy evolution, and permeability [74-77]. Then, some works proposed the of liquid nitrogen freeze-thaw cycling stimulation technique and investigated the influence of freeze-thaw time, number of freeze-thaw cycles, coal moisture content, and coal rank on the coal properties such as pore structure and permeability [78].

Despite the liquid nitrogen freeze-thaw technique can save water resources and reduce the reservoir damage, it also faces some problems and changes:
TABLE 1: Focused areas of different studies.

\begin{tabular}{lc}
\hline Focused area & References \\
\hline Permeability and porosity & Qin et al. [20, 71, 78, 79] \\
Mechanical behavior & Coetzee et al. [74] and Cai et al. [80] \\
Field application & McDaniel et al. $[19,73]$ \\
Crack propagation & Cha et al. $[75,76]$ \\
\hline
\end{tabular}

(i) The cost of cryogenic liquid nitrogen stimulation technique is higher than hydraulic techniques

(ii) The level of technology and equipment need to be further developed so that the liquid nitrogen can be kept in a low-temperature status

(iii) The created fractures close up faster because it is unable to adequately carry proppant due to the low liquid viscosity

2.3.2. Microwave Heating Stimulation Technique. In the oil exploitation field, steam injection is widely used as a stimulation technique to improve oil production, but the rapid loss 


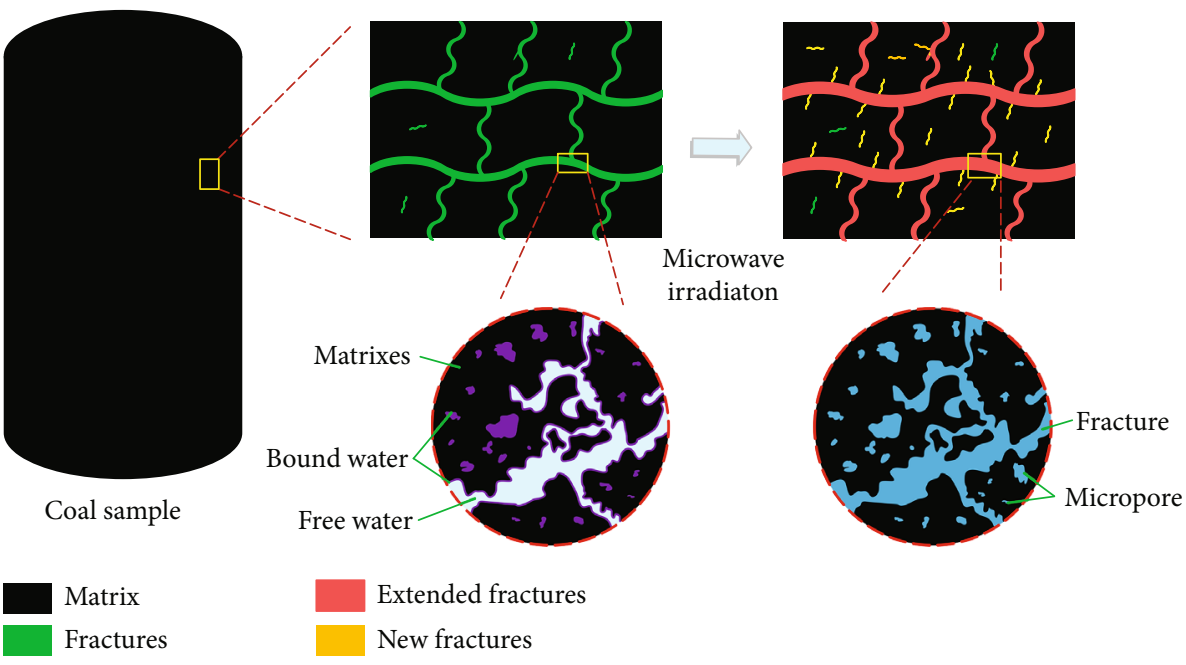

FIGURE 15: Schematic diagram for the coal seam after microwave heating stimulation.

of heat limits the stimulation efficiency as the depth grows [81]. Therefore, in 1956, some works proposed the microwave heating stimulation technique, which uses the microwave irradiation to heat coal medium to improve the oil and gas production. As shown in Figure 15, on the one hand, the heating-induced local stress causes the form and expansion of fracture. On the other hand, the high temperature evaporates the water in pores so that the permeability increases. Therefore, the microwave heating stimulation technique has been widely used in oil exploration [82-85]. However, the gas flow in a coal seam is different from the oil in reservoirs. The high temperature can eliminate the water-block effect and reduce gas adsorption capacity, so it is a technically feasible stimulation technique for coal seams. Figure 16 is the conceptual design of the microwave heating stimulation technique.

Over the past several decades, some work about microwave heating for improving gas production was reported [87, 88]. In 2006, Li et al. [89] deemed that microwave heating can improve the gas production by cleaning up the waterblock effect via a series of laboratory study and concluded that microwave heating has an encouraging future in field application. In 2007, Denney [90] summed up the highlights of Li's work and pointed out that the gas permeability can be enhanced to $102 \%$ to $266 \%$ after microwave heating depending on the heating time. Then, the influence of microwave heating on the pore structure, cleat, fractal dimension, chemical component, and mechanical properties was reported by some work. Moreover, Li et al. [91, 92] constructed an electromagnetic-thermal-mechanical model of coalbed methane extraction and further provided the theoretical basis of the microwave heating stimulation technique. However, most of the works are laboratory study and numerical simulation, and it is still lack of the field test.

The advance of this technique stilling faces significant challenges, such as (i) the high-quality microwave radiation antenna is required to be developed, (ii) The heating parameters including time and frequency are required to be determined, (iii) the influence range of microwave heating is

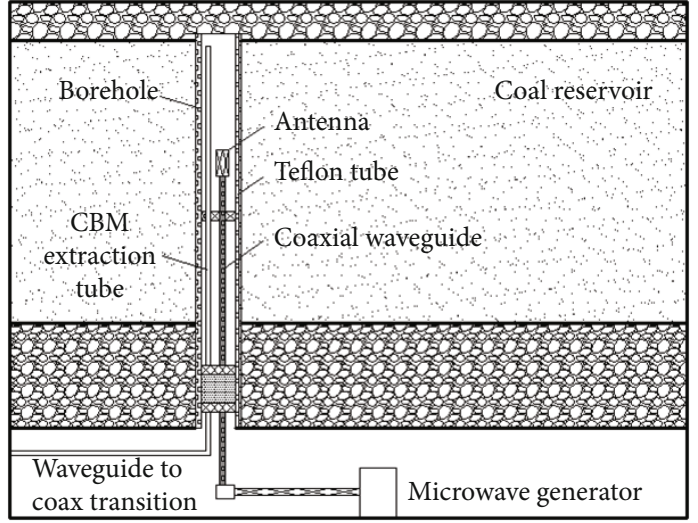

Figure 16: The conceptual design of the microwave heating stimulation technique [86].

needed to be mastered, and (iv) this method may be more suitable for the surface well extraction. It may induce the coal spontaneous combustion of gob if it was directly applied to underground coal mining operations.

\subsection{Chemical Stimulation Techniques}

2.4.1. Acidification Reconstruction Coal Seam Stimulation Technique. There are lots of minerals in the coal containing the carbonate and clay minerals, which occupy the channel of gas transport. The acid solution can dissolve the minerals in the coal and swell coal matrix to improve the gas permeability, as shown in Figure 17. Previous studies about the acidification reconstruction coal seam stimulation technique primarily concentrated on the laboratory study. The acidification reconstruction can be classified into two kinds: lowpressure acidification and acid fracturing. The low-pressure acidification is to pump the acid solution into coal seam under the pressure below the coal damage. Conversely, the acid fracturing is similar to the hydraulic fracturing.

Since the 1890s, the acidification technique was proposed to improve oil production. At present, it has become a conventional stimulation technique in oil and gas exploration. 


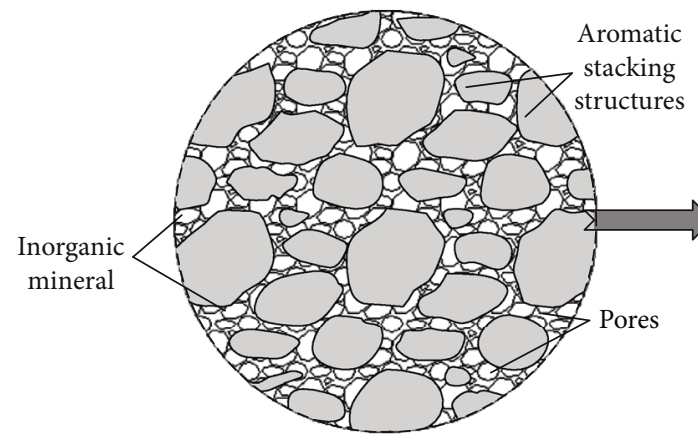

(a) Before acidification

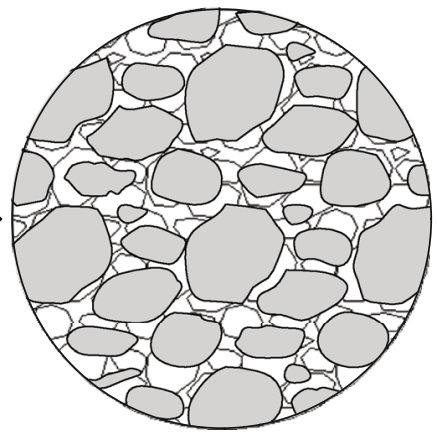

(b)After acidification

FIgURE 17: Evolution of pore in coal before and after acidification.

However, only a few field trial about coal seam acidification reconstruction was reported $[93,94]$. In China, the field trials of acidification reconstruction in coal seam have been carried out in Shanxi Province, such as Shihe coal mine and Tunliu coalbed gas well $[95,96]$. The results showed that the acidification reconstruction can greatly improve the gas permeability.

The key challenges of acidification include

(i) Potential contamination to groundwater

(ii) Pipe and pump corrosion

(iii) Unsuitable for the coal seam with low mineral content

2.4.2. Microbial Stimulation. Microbial stimulation is to use the microbial to degrade the small molecular substances in coal, thereby improving the gas permeability and enhancing gas production. In the early 20th century, some scholars realized that microbial can metabolize coal [97]. Then, more and more studies about microbial cultures and enzyme preparations to metabolize coal were reported $[98,99]$. In 2003, Faiz et al. [100] reported that the "bio-enhancement" could improve the CBM well production based on the data from Sydney Gas Company. Then, Guo et al. [101] experimentally studied the influence of microbial on the coal and concluded that the microbial degradation is able to increase the reservoir permeability. However, few works about the field application of microbial stimulation were reported.

Therefore, it is still facing many challenges before being extended to field applications, some of which are

(i) A suitable microorganism is required to be selected

(ii) Strictly requirements on breeding environment (e.g., temperature) for microbial in the coal seam

(iii) It is difficult to degrade high-rank coal by microbial stimulation

(iv) The time required for microbial stimulation to take effect is significantly long, thus hard to improve productivity in short term

2.4.3. Gas Injection: $\mathrm{CO}_{2}-E C B M$ and $\mathrm{N}_{2}$-ECBM. The idea of injection gas, such as $\mathrm{CO}_{2}, \mathrm{~N}_{2}$, flue gas, and mix gas, to improve the enhanced coalbed methane recovery was proposed in the 1900s $[102,103]$. In 1995, the $\mathrm{CO}_{2}$-ECBM field test was carried out in Allison Unit operated by Burlington Resources, and the $\mathrm{CO}_{2}$ injection was suspended in 2001. There were 16 methane production wells, $4 \mathrm{CO}_{2}$ injection wells, and one pressure observation well in the filed area [104]. Similarly, in 1998, the $\mathrm{N}_{2}$-ECBM field test was carried out in Tiffany Unit operated by BP America, and the $\mathrm{N}_{2}$ injection was suspended in 2002. The field area included 34 methane production wells and 12 nitrogen injection wells [105]. Both 2 field test showed that the gas injection can enhance methane recovery. After that, the gas injection to enhance coalbed methane recovery was carried out in Japan, Australia, China, and so on [106]. Figure 18 is the schematic diagram of gas injection to enhance the coalbed methane recovery. The inert gas, including $\mathrm{CO}_{2}, \mathrm{~N}_{2}$, flue gas, and mix gas, is injected from the injection well to displace the methane in the fracture of coal. Furthermore, the injected gas can reduce the partial pressure of methane and lead to methane desorption.

$\mathrm{CO}_{2}$-ECBM as a stimulation technique has been extensively studied. $\mathrm{CO}_{2}$ possesses stronger adsorption capacity, and it can reduce the partial pressure of methane, leading to the desorption of methane from coal pores. Moreover, the acid solution generated after the $\mathrm{CO}_{2}$ dissolved into the water can dissolve the minerals in and improve the connectivity of pores, resulting in the enhancement in permeability. In addition, the $\mathrm{CO}_{2}$-ECBM is also a possible geological sequestration method to reduce the greenhouse effect $[108,109]$.

The main challenges facing $\mathrm{CO}_{2}$-ECBM are (i) the most important issue; $\mathrm{CO}_{2}$ can induce the swelling deformation of coal matrix due to the strong adsorption capacity, which can cause the decline in permeability and thus the reduction in $\mathrm{CO}_{2}$ injection rate, especially in the low-permeability coal seam. For instance, White et al. [110] reported that the gas permeability drops back after $\mathrm{CO}_{2}$ was injected into coal seam in the field test in America, European Union, and Japan. Zhang et al., [111] used a novel in-situ reservoir condition X-ray microcomputed tomography flooding apparatus to observe the coal cleat and concluded that the $\mathrm{CO}_{2}$-induced the swelling stress can make the fracture closure and thus decrease the gas permeability, (ii) the sorption-induced swelling deformation may cause a stress concentration zone, leading to a great threat to the stability of the caprock and the 


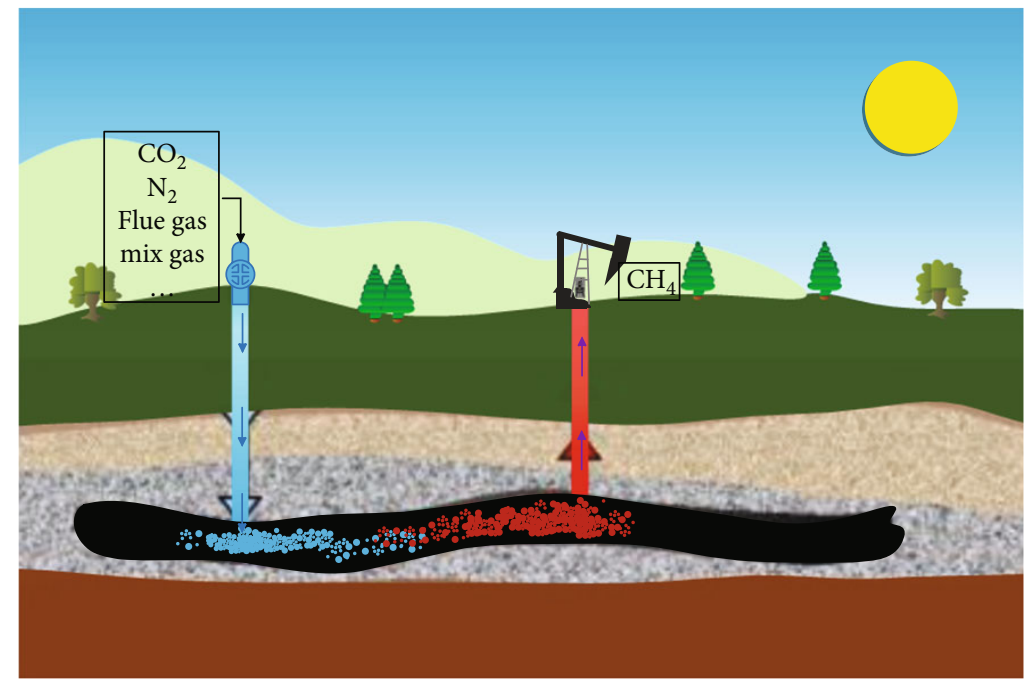

Figure 18: Illustration of the $\mathrm{CO}_{2}$-ECBM technique to stimulate coal seam methane gas production [107].

long-term sequestration of $\mathrm{CO}_{2}$, (ii) $\mathrm{CO}_{2}$-ECBM only can be applied to coal seams with good caprock, otherwise, it may pose $\mathrm{CO}_{2}$ leakage risk, (iv) the well technology and monitoring gas migration also act an important role in $\mathrm{CO}_{2}$-ECBM [103], and (v) the $\mathrm{CO}_{2}$-induced gas outburst should be evaluated if it is used in underground gas extraction.

Similarly, the injection of $\mathrm{N}_{2}$ is also used to enhance coalbed methane recovery. Especially for the $\mathrm{CO}_{2}$-rich coal seam, the $\mathrm{N}_{2}$-ECBM is a better method to improve methane production and reduce the risk of gas outburst $[112,113]$. After the injection of $\mathrm{N}_{2}$, it can displace the free $\mathrm{CH}_{4} / \mathrm{CO}_{2}$ in the fracture, break the equilibrium of gas, and reduce the partial pressure of $\mathrm{CH}_{4} / \mathrm{CO}_{2}$, leading to the desorption of $\mathrm{CH}_{4} / \mathrm{CO}_{2}$ from the coal matrix [114]. Compared with $\mathrm{CH}_{4}$ and $\mathrm{CO}_{2}, \mathrm{~N}_{2}$ possesses the weakest adsorption capacity. Therefore, the injection of $\mathrm{N}_{2}$ is regarded as one of the methods to recover the coal seam permeability reduction induced by $\mathrm{CO}_{2}$-ECBM. In addition, the cost of $\mathrm{N}_{2}$-ECBM is relatively lower because $\mathrm{N}_{2}$ can be obtained easily from the air. Table 2 is the summary of gas injection for improving methane production.

Although $\mathrm{N}_{2}$-ECBM possesses the above advantages, such as small sorption-induced swelling deformation and low cost, it still faces a number of technical challenges: (i) The breakthrough of $\mathrm{N}_{2}$ occurred fairly quickly, leading to the decline in methane concentration of production well, (ii) $\mathrm{N}_{2}$ was commonly produced by the cryogenic air separation plants, which are unable to work continuously at high temperature, leading to low injection efficiency, (iii) the methane in micropores cannot be completely displaced by $\mathrm{N}_{2}$ due to the lower adsorption capacity.

2.5. Summary. As described above, the coal seam stimulation techniques were classified into three groups based on the stimulation mechanism. In total, twelve common stimulation techniques were reviewed in this work, and the key advantages and disadvantages of each technique are explained in Table 3 .

\section{Results and Comparison}

3.1. Definition of Stimulation Effectiveness Index. As described above, some methods were used to stimulate coal seams by improving the porosity and thus enhancing the permeability. In this case, it is easy to judge their stimulation effectiveness by comparing the change in porosity or permeability. However, some large-range stimulation techniques are to create new fractures or to displace the methane to improve the gas production. For those techniques, it is very difficult to subjectively compare their effectiveness by a single index.

In order to provide a meaningful comparison, the results for the above stimulation techniques were further classified into two types: field applications and laboratory methods. In this work, the liquid nitrogen, microwave heating, highvoltage electric, acidification, and microbial stimulation techniques were regarded as the laboratory methods, and the rest were classified as the large scale field applications. The data from previous literature were used to compare the stimulation effectiveness.

For laboratory methods, permeability is one of the most appropriate parameters to judge stimulation effectiveness. However, it is generally believed that the permeability based on laboratory test is controlled by the temperature, confining stress and gas pressure. It is inaccurate to compare stimulation effectiveness by permeability. Therefore, the porosity change ratio was used to judge the stimulation effectiveness instead of permeability, and the expression is shown in Eq. (1).

$$
\eta=\frac{\phi_{\text {post }}-\phi_{\text {pre }}}{\phi_{\text {pre }}} \times 100 \%
$$

where $\eta$ is the porosity change ratio (\%), $\phi_{\text {pre }}$ is the pretreatment porosity (\%), and $\phi_{\text {post }}$ is the post-treatment porosity (\%). 
TABLE 2: The summary of gas injection for improving methane production.

\begin{tabular}{|c|c|c|c|c|}
\hline Coal & Focused area & Research method & Gas & References \\
\hline Australia coal & Nitrogen displaces the $\mathrm{CO}_{2}$ & Experiment & $\mathrm{N}_{2} / \mathrm{CO}_{2}$ & {$[113]$} \\
\hline $\begin{array}{l}\text { Ishikari coalfield (Japan) } \\
\text { Taoyuan coal } \\
\text { Mine, Qingdong coal mine, and } \\
\text { Qincheng coal mine (China) }\end{array}$ & Adsorption capacity & Experiment & $\mathrm{N}_{2} / \mathrm{CO}_{2} / \mathrm{CH}_{4}$ & {$[115,116]$} \\
\hline $\begin{array}{l}\text { Sydney } \\
\text { Basin (Australia) }\end{array}$ & Permeability & Experiment/simulation & $\mathrm{N}_{2} / \mathrm{CO}_{2}$ & {$[114]$} \\
\hline- & Permeability & Simulation & $\mathrm{CO}_{2} / \mathrm{CH}_{4}$ & {$[117]$} \\
\hline $\begin{array}{l}\text { Southern Sydney } \\
\text { Basin (Australia), } \\
\text { Tashan coal mine (China) }\end{array}$ & Injection parameters & Simulation/experiment & $\mathrm{N}_{2} / \mathrm{CO}_{2}$ & {$[112,118]$} \\
\hline- & Mechanical characteristics & Review & $\mathrm{CO}_{2}$ & {$[4]$} \\
\hline Tashan coal mine (China) & Mechanical characteristics & Experiment & $\mathrm{CO}_{2}$ & [119] \\
\hline San Juan basin (USA) & Reservoir modeling & Field test & $\mathrm{N}_{2} / \mathrm{CO}_{2}$ & {$[104,105]$} \\
\hline Xinzhouyao coal mine and Tangshan coal mine (China) & Diffusion & Simulation/experiment & $\mathrm{CO}_{2} / \mathrm{CH}_{4}$ & [106] \\
\hline Pingdingshan ten coal mine (China) & Matrix swelling & Experiment & $\mathrm{CO}_{2}$ & [111] \\
\hline Sydney Basin (Australia) & Matrix swelling & Experiment & $\mathrm{CO}_{2} / \mathrm{CH}_{4}$ & {$[120]$} \\
\hline - & Injection parameters & Simulation & $\mathrm{CO}_{2} / \mathrm{CH}_{4}$ & {$[121,122]$} \\
\hline
\end{tabular}

For the large scale field applications, the ratio of average gas flow before and after the stimulation was used to judge the stimulation effectiveness. The productivity index was not used, because a lack of published data to calculate this value. The ratio can be expressed as

$$
n=\frac{q_{\text {post }}}{q_{\text {pre }}}
$$

where $q_{\text {pre }}$ and $q_{\text {post }}$ are the average gas flow rate before and after stimulation, respectively $\left(\mathrm{m}^{3} / \mathrm{min}\right)$.

\subsection{Comparison of Stimulation Effectiveness}

3.2.1. Comparison of Stimulation Effectiveness at LaboratoryScale. Figure 15 shows the rate of porosity change of different stimulation methods in terms of maximum vitrinite reflectance. As listed in Table 4, these data are from the literature of $[20,50,72,78,79,86,94,96,123-132]$. The porosity change rate $(\eta)$ is classified as three grades: low-grade $\eta<$ $50 \%$, medium-grade $50 \%<\eta \leq 100 \%$, and high-grade $\eta \geq$ $100 \%$.

The results show that three stimulation methods have achieved high-grade enhancement: high-voltage electric, liquid nitrogen, and acidification. It is noticed that in Figure 19 the peak $\eta$ is close to $600 \%$ for the high-voltage electric stimulation method, but it may not be representative of the common effectiveness of high-voltage electric stimulation method, because for the rest experimental data only one point actually exceeds $100 \%$. Three kinds of methods are fallen into the medium range of 50\%-100\%: microwave heating, liquid nitrogen, and high-voltage electric. For the microbial stimulation technique, all the data are within the low grade of $\eta<50 \%$. In addition, it is observed that the stimulation effectiveness for coal samples with middle-low rank always performs better for all listed the stimulation methods. For instance, the vitrinite reflectance for all the coal samples with $\eta \geq 100 \%$ rate is always in the range of $1.5 \%-2.5 \%$, which can be grouped as the middle-rank coal. The difficulty in improving the porosity of high-rank coal is largely due to the higher strength and more stable macromolecular. For the low-rank coal, although it is easier to enhance the porosity by using the stimulation technique, the increment of porosity is limited due to its extremely developed micropore structures. For the middle-rank coal, it possesses the moderate strength and molecular structure, and it has a greater enhancement potential due to the lesser porosity. Therefore, middle-rank coal has the best stimulation effectiveness.

Furthermore, the duration of stimulation is also one of the most important parameters. The relationship between duration and pore change ratio is shown in Figure 20. Please be noted that coal can be broken down in an extremely short time when being imposed to a high-voltage electric stimulation technique, approximately in a few microseconds. However, it could take several months, even years to improve the porosity of coal using the microbial stimulation method even under the controllable laboratory conditions. For this reason, in this work, only the three stimulation methods (i.e., liquid nitrogen, microwave heating, and acidification) were plotted in Figure 20.

It is observed that the microwaving heating stimulation method takes only 4-120 seconds, and it still shows good stimulation effectiveness. For the liquid nitrogen stimulation technique, most of the points are located in the range from 10 minutes to 300 minutes, and the porosity change ratio is less than $100 \%$. Nevertheless, the ratio can be more than $100 \%$ when the treatment time is over 80 hours. By contrast, the porosity change ratio is very small when the treatment time is 1 minute. 
TABLE 3: Advantages and disadvantages of different stimulation techniques.

\begin{tabular}{|c|c|c|c|}
\hline Classification & Stimulation technique & Advantages & Disadvantage \\
\hline \multirow[t]{2}{*}{ Thermal stimulation } & Cryogenic liquid nitrogen & $\begin{array}{l}\text { (1) Pollution-free } \\
\text { (2) Water saving }\end{array}$ & $\begin{array}{l}\text { (1) High cost } \\
\text { (2) Cracks closed quickly } \\
\text { (3) Immature technology }\end{array}$ \\
\hline & Microwave heating & $\begin{array}{l}\text { (1) Water saving } \\
\text { (2) Reusable }\end{array}$ & $\begin{array}{l}\text { (1) Immature technology } \\
\text { (2) Unsuitable for CMM extraction }\end{array}$ \\
\hline \multirow{5}{*}{ Mechanical stimulation } & $\begin{array}{l}\text { Hydraulic fracturing } \\
\text { Hydraulic slotting } \\
\text { Hydraulic punching }\end{array}$ & $\begin{array}{l}\text { (1) Good performance } \\
\text { (2) Low cost } \\
\text { (3) Short duration } \\
\text { (4) Mature technology }\end{array}$ & $\begin{array}{l}\text { (1) Wasting water } \\
\text { (2) Induced earthquake } \\
\text { (3) Environmental pollution }\end{array}$ \\
\hline & High-voltage electric fracturing & $\begin{array}{l}\text { (1) Short duration } \\
\text { (2) Pollution-free } \\
\text { (3) Reusable }\end{array}$ & $\begin{array}{l}\text { (1) High cost } \\
\text { (2) Immature technology }\end{array}$ \\
\hline & Deep-hole blasting & $\begin{array}{l}\text { (1) Low cost } \\
\text { (2) Short duration } \\
\text { (3) Mature technology }\end{array}$ & $\begin{array}{l}\text { (1) Collapse } \\
\text { (2) Uncontrollable fracture direction } \\
\text { (3) Small range }\end{array}$ \\
\hline & Liquid $\mathrm{CO}_{2}$ phase-change fracturing & $\begin{array}{l}\text { (1) Controllable blasting pressure } \\
\text { (3) Reducing greenhouse gas } \\
\text { (2) Pollution-free } \\
\text { (3) Water saving }\end{array}$ & $\begin{array}{l}\text { (1) Collapse } \\
\text { (2) Uncontrollable fracture direction } \\
\text { (3) Small range }\end{array}$ \\
\hline & $\begin{array}{l}\text { Underground CMM extraction under } \\
\text { mining-induced stress-relieved seams }\end{array}$ & $\begin{array}{l}\text { (1) Good performance } \\
\text { (2) Mature technology } \\
\text { (3) Low risk for CMM extraction }\end{array}$ & $\begin{array}{l}\text { (1) Unsuitable for single coal seam } \\
\text { (2) Long duration }\end{array}$ \\
\hline \multirow{4}{*}{ Chemical stimulation } & Acidification reconstruction & - & $\begin{array}{l}\text { (1) Environmental pollution } \\
\text { (2) Clay swelling }\end{array}$ \\
\hline & Microbial stimulation & - & $\begin{array}{l}\text { (1) Long duration } \\
\text { (2) Uncontrollable influence range } \\
\text { (3) Low stimulation effectiveness }\end{array}$ \\
\hline & $\mathrm{CO}_{2}-\mathrm{ECBM}$ & $\begin{array}{l}\text { (1) Good performance } \\
\text { (2) Reducing greenhouse gas } \\
\text { (3) Pollution-free } \\
\text { (4) Water saving }\end{array}$ & $\begin{array}{l}\text { (1) Matrix swelling } \\
\text { (2) Long duration }\end{array}$ \\
\hline & $\mathrm{N}_{2}-\mathrm{ECBM}$ & $\begin{array}{l}\text { (1) Good performance } \\
\text { (2) Pollution-free } \\
\text { (3) Water saving }\end{array}$ & $\begin{array}{l}\text { (1) Short break-through time } \\
\text { (2) Long duration }\end{array}$ \\
\hline
\end{tabular}

TABLE 4: Data source of laboratory-scale stimulation effectiveness.

\begin{tabular}{lc}
\hline Stimulation method & Data source \\
\hline Liquid nitrogen & References $[20,72,78,79,123]$ \\
Microwave heating & References $[86,124-127]$ \\
High-voltage electric & References $[50,128,129]$ \\
Acidification & References $[94,96,130]$ \\
Microbial & References $[131,132]$ \\
\hline
\end{tabular}

The duration of acidification ranges from $24 \mathrm{~h}$ to $48 \mathrm{~h}$, which takes the longest to show its effectiveness compared with the other two methods. In addition, both the microwave heating and liquid nitrogen stimulation technique are sensitive to the treatment time, and the porosity change ratio increases with the increase in treatment time. However, the acidification does not show the same trend of time sensitivity, which may be because the long treatment time may cause the expansion of clay mineral and thus leading to the reduction in porosity. Moreover, the effectiveness of acidification is largely controlled by mineral content.
3.2.2. Comparison of Stimulation Effectiveness at Field-Scale. The stimulation effectiveness for five kinds of methods was plotted in Figure 21, and the data are from literatures [64, 133-161], as shown in Table 5.

It is observed that the maximum increment of $n$ value is approximately 140 times for hydraulic fracturing. As the extraction time grows, the stimulation effectiveness gradually reduces. The effectiveness is particularly good in the initial extraction stage (less than 15 days) for hydraulic slotting, deep-hole blasting, and liquid $\mathrm{CO}_{2}$ phase-change fracturing. It is difficult to judge the effectiveness of hydraulic fracturing in the initial stage due to the lack of data. However, it can be concluded that the hydraulic fracturing possesses the best stimulation effectiveness.

Results presented in Figure 21 show that the stimulation effectiveness of hydraulic slotting is better than hydraulic punching, particularly at the initial stage. This is because the hydraulic punching can wash out lots of coal with gas, which is unable to be captured and taken into account. Furthermore, the liquid $\mathrm{CO}_{2}$ phase-change fracturing can 


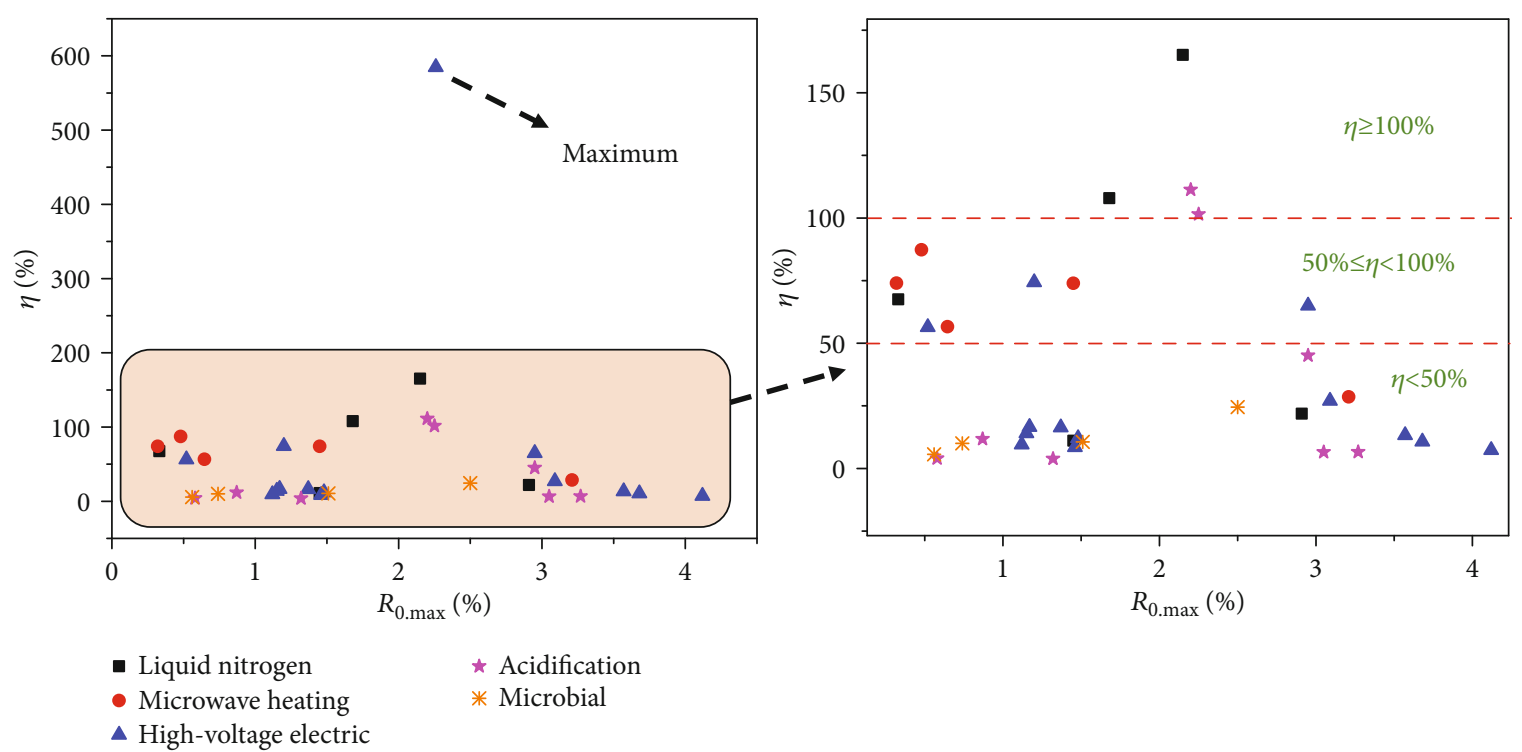

FIGURE 19: The pore change rate of different stimulation methods with maximum vitrinite reflectance (the data come from the literatures [20, $50,72,78,79,86,94,96,123-132])^{* *}$ Note: (i) For the same coal sample with the same stimulation method, only the maximum $\eta$ was used for plotting, and (ii) for the samples using microbial stimulation, the total pore volume was substituted into Eq.(1) instead of porosity because of the lack of data.

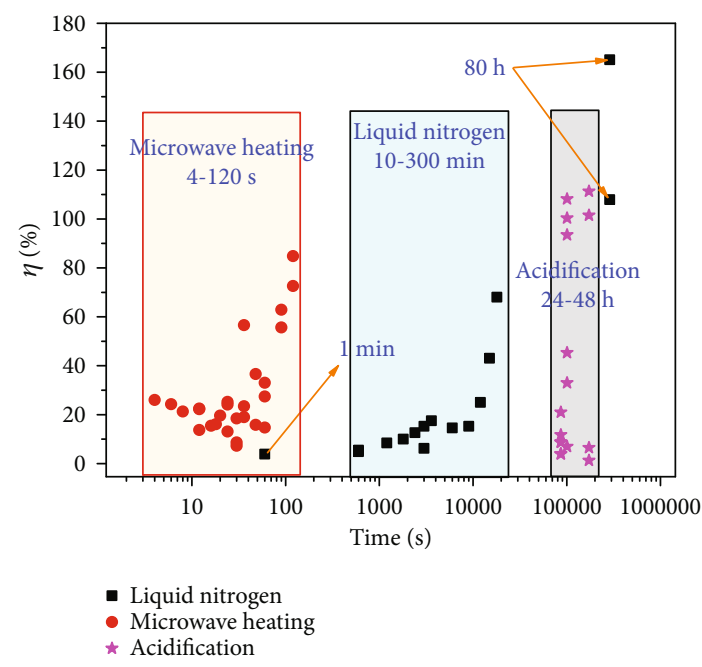

FIGURE 20: The relation between duration and pore change rate (the data come from the literatures $[20,72,78,79,86,94,96,123-127,130])$.

effectively improve gas production up to 60 days. The liquid $\mathrm{CO}_{2}$ phase-change fracturing is similar to the deep-hole blasting, but it also can replace the methane in pores because coal has stronger adsorption affinity to $\mathrm{CO}_{2}$. It is noted that some data for liquid $\mathrm{CO}_{2}$ phase-change fracturing is less than deep-hole blasting because the power of liquid $\mathrm{CO}_{2}$ phase change is smaller than deep-hole blasting. Overall, the stimulation effectiveness of liquid $\mathrm{CO}_{2}$ phase-change fracturing is better than deep-hole blasting, while the deep-hole blasting is more stable.

Please be noted that we did not plot the extraction data for $\mathrm{CO}_{2}$-ECBM, $\mathrm{N}_{2}$-ECBM, and underground CMM extraction under mining-induced stress-relieved seams. For the $\mathrm{CO}_{2}$-ECBM and $\mathrm{N}_{2}$-ECBM, although some projects have been carried out to enhance CBM recovery in some countries, it is difficult to directly detect the gas production due to the existence of inert gas. A common practice globally is usually to calculate it via reservoir simulation, but it is concluded that the gas injection can greatly improve the CBM recovery while the duration and cost are very high compared with other methods.

For the underground CMM extraction under mininginduced stress-relieved seams, it is the first option in the CMM in China. However, the extraction efficiency is significantly affected by the coal mining operations, so it is difficult to compare it in a single index. Compared with other methods, the underground CMM extraction under mininginduced stress-relieved seams possesses a larger scope and better stimulation effectiveness. However, it is only used in the multicoal seams, and the duration is the longest.

3.3. Ranking of Stimulation Effectiveness. It is undeniable that the stimulation techniques should be evaluated comprehensively, and facts like the effectiveness, duration, environment, and cost should be considered in the evaluation. With such large of stimulation methods, it is not practical to consider all factors simultaneously. In this paper, we tried to evaluate a stimulation technique according to three key factors: effectiveness, influence zone (i.e., stimulation area), duration, and environment. Every index was divided into three categories. Similar to the previous approach, these techniques aforementioned were divided into two parts and evaluated, respectively: Laboratory-scale stimulations and field-scale stimulations. This is because some techniques are still in the laboratory-study stage. The summary of the comparison is listed in Table 6 and Figure 22.

For the laboratory-scale stimulation technique, the stimulation effectiveness is classified in three grades according to 


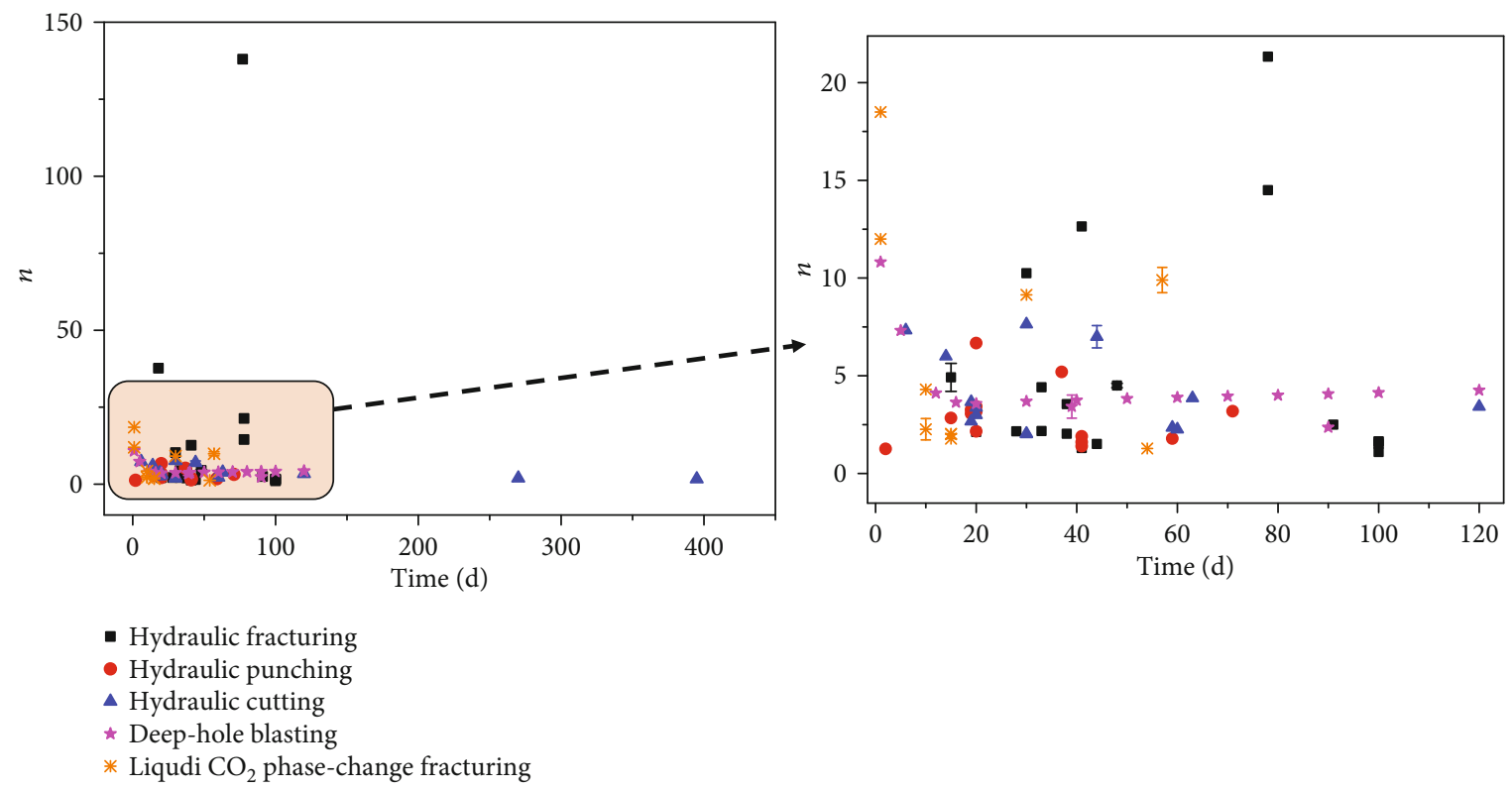

Figure 21: The growth multiples of average gas flow for different stimulation techniques (the data come from the literatures [64, 133-161]).

TABLE 5: Data sources of field-scale stimulation effectiveness.

\begin{tabular}{lc}
\hline Stimulation method & Data source \\
\hline Hydraulic fracturing & References [133-140] \\
Hydraulic punching & References [141-145] \\
Hydraulic cutting & References [146-154] \\
Deep-hole blasting & References [155-157] \\
Liquid $\mathrm{CO}_{2}$ phase-change fracturing & References [61, 158-161] \\
\hline
\end{tabular}

the results in Section 3.2.1 Cryogenic liquid nitrogen and acidification reconstruction has the best performance, followed by high-voltage electric fracturing, and the last is the microbial stimulation. Therefore, they are classified as three grades, respectively.

For the influence zone, it is concluded that the temperature and electric current can have the longest influence zone. For the acidification fluid and microbial has a shorter influence range because of the complicated coal seam conditions.

Furthermore, it is undeniable that high-voltage electric fracturing has the shortest duration because it can be done suddenly, so high-voltage electric fracturing is classified as grade 3 . Then, cryogenic liquid nitrogen, microwave heating, and acidification reconstruction are regarded as grade 2 and microbial stimulation is classified as grade 1 according to the results in Figure 15.

For the environment index, as we all know, cryogenic liquid nitrogen is a type of clean gas, so it is reasonable to consider it causes no environmental pollution. However, microwave heating and high-voltage electric fracturing may produce some harmful gas during the stimulation process due to the high temperature, although the amount may be small, thus they are classified as grade 2 . Acidification reconstruction and microbial stimulation are regarded as grade 1 , because they undoubtedly pollute the groundwater.
For the total score, cryogenic liquid nitrogen and highvoltage electric fracturing have good performance in total score, followed by microwave heating. Furthermore, acidification reconstruction and microbial stimulation have the worst total score. In summary, we think the cryogenic liquid nitrogen, high-voltage electric fracturing and microwave heating have a certain of application prospects.

For the field-scale stimulation technique, the stimulation effectiveness is classified three grades according to the results in Section 3.2.2. Hydraulic fracturing has the best stimulation effectiveness, so it is regarded as grade 3 in stimulation effectiveness. Furthermore, hydraulic slotting and hydraulic punching liquid $\mathrm{CO}_{2}$ phase-change fracturing are classified as grade 2, while deep-hole blasting is regarded as grade 1 . In addition, there is no doubt that underground CMM extraction under mining-induced stress-relieved seams and gas injection also should be classified as grade 3 as their superiority has been proven by extensive field trials.

For the influence range, hydraulic fracturing, gas injection, and underground CMM extraction under mininginduced stress-relieved seams are regarded as grade 3 because their influence range is generally more than ten meters and even to hundreds of meters. Then, liquid $\mathrm{CO}_{2}$ phasechange fracturing is classified as grade 1 as its influence range is always less than 3 meters due to its small blasting pressure, and the other techniques are classified as grade 2 because their influence range is about 3 meters to 10 meters. For the duration, gas injection, and underground CMM extraction under mining-induced stress-relieved seams are regarded as grade 1 as their durations are always more than several months and even to several years. The other techniques are classified as grade 3 because their durations are generally less than 1 week. It is noticed that the duration in this ignores the time of equipment installation. Therefore, we only considered the stimulation duration of the technique. For the environment, all hydraulic techniques are regarded as grade 1 
TABLE 6: Comprehensive assessment.

\begin{tabular}{|c|c|c|c|c|c|c|}
\hline \multirow[b]{2}{*}{ Classification } & \multirow[b]{2}{*}{ Stimulation technique } & \multicolumn{4}{|c|}{ Factor } & \multirow{2}{*}{$\begin{array}{l}\text { Total } \\
\text { score } \\
(\sqrt{ })\end{array}$} \\
\hline & & $\begin{array}{l}\text { Stimulation } \\
\text { effectiveness }\end{array}$ & $\begin{array}{l}\text { Influence } \\
\text { range }\end{array}$ & Duration & Environment & \\
\hline \multirow{5}{*}{$\begin{array}{l}\text { Laboratory-scale } \\
\text { stimulation technique }\end{array}$} & Cryogenic liquid nitrogen (CLN) & $\sqrt{ } \sqrt{ } \sqrt{ }$ & $\sqrt{ } \sqrt{ } \sqrt{ }$ & $\sqrt{ } \sqrt{ }$ & $\sqrt{ } \sqrt{ } \sqrt{ }$ & 11 \\
\hline & Microwave heating (MH) & $\sqrt{ } \sqrt{ }$ & $\sqrt{ } \sqrt{ } \sqrt{ }$ & $\sqrt{ } \sqrt{ }$ & $\sqrt{ } \sqrt{ }$ & 9 \\
\hline & High-voltage electric fracturing (HVEF) & $\sqrt{ } \sqrt{ }$ & $\sqrt{ } \sqrt{ }$ & $\sqrt{ } \sqrt{ }$ & $\sqrt{ } \sqrt{ }$ & 10 \\
\hline & Acidification reconstruction (AR) & $\sqrt{ } \sqrt{ } \sqrt{ }$ & $\sqrt{ } \sqrt{ }$ & $\sqrt{ } \sqrt{ }$ & $\sqrt{ }$ & 7 \\
\hline & Microbial stimulation (MS) & $\sqrt{ }$ & $\sqrt{ } \sqrt{ }$ & $\sqrt{ }$ & $\sqrt{ }$ & 5 \\
\hline \multirow{7}{*}{$\begin{array}{l}\text { Field-scale } \\
\text { stimulation technique }\end{array}$} & Hydraulic fracturing $(\mathrm{HF})$ & $\sqrt{ } \sqrt{ }$ & $\sqrt{ } \sqrt{ } \sqrt{2}$ & $\sqrt{ } \sqrt{ }$ & $\sqrt{ }$ & 10 \\
\hline & Hydraulic slotting $(\mathrm{HS})$ & $\sqrt{ } \sqrt{ }$ & $\sqrt{ } \sqrt{ }$ & $\sqrt{ } \sqrt{ }$ & $\sqrt{ }$ & 8 \\
\hline & Hydraulic punching (HP) & $\sqrt{ } \sqrt{ }$ & $\sqrt{ } \sqrt{ }$ & $\sqrt{ } \sqrt{ }$ & $\sqrt{ }$ & 8 \\
\hline & Deep-hole blasting (DHB) & $\sqrt{ }$ & $\sqrt{ } \sqrt{ }$ & $\sqrt{ } \sqrt{ }$ & $\sqrt{ } \sqrt{ }$ & 8 \\
\hline & Liquid $\mathrm{CO}_{2}$ phase-change fracturing $\left(\mathrm{LCO}_{2} \mathrm{PCF}\right)$ & $\sqrt{ } \sqrt{ }$ & $\sqrt{ }$ & $\sqrt{ } \sqrt{ }$ & $\sqrt{ } \sqrt{ }$ & 9 \\
\hline & $\begin{array}{l}\text { Underground CMM extraction under mining- } \\
\text { induced stress-relieved seams (EUMISRS) }\end{array}$ & $\sqrt{ } \sqrt{ }$ & $\sqrt{ } \sqrt{ }$ & $\sqrt{ }$ & $\sqrt{ }$ & 8 \\
\hline & Gas injection (GI) & $\sqrt{ } \sqrt{ }$ & $\sqrt{ } \sqrt{ }$ & $\sqrt{ }$ & $\sqrt{ } \sqrt{ }$ & 10 \\
\hline
\end{tabular}

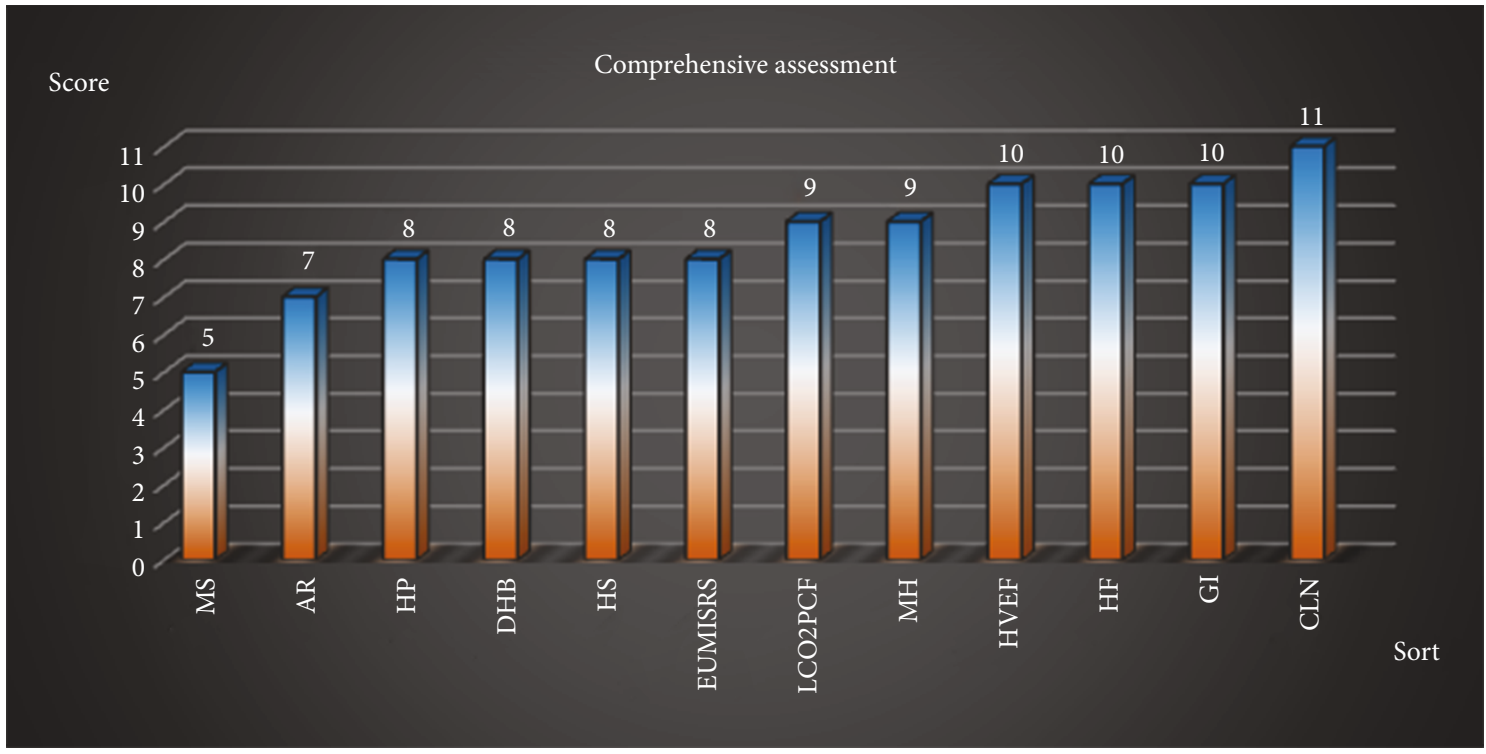

Figure 22: Comprehensive assessment.

because they would waste lots of water and pollute the groundwater.

In addition, underground CMM extraction under mininginduced stress-relieved seams also is classified as grade 1 as it may cause surface subsidence and groundwater pollution. Then, deep-hole blasting is classified as grade 2 because it may induce gas disaster and produce some harmful gas although its amount is very small. Liquid $\mathrm{CO}_{2}$ phase-change fracturing is regarded as grade 3 as it can reduce greenhouse gas.

For the total score, hydraulic fracturing and gas injection have the best performance, followed by liquid $\mathrm{CO}_{2}$ phasechange fracturing. However, hydraulic fracturing is so bad for the environment and it has been limited in some cities or countries, although it has the best effectiveness and lowest cost. Therefore, the gas injection may be able to act a crucial role in ECBM in the future.

\section{Conclusions and Recommendations}

In this paper, the coal seam stimulation techniques were classified as three kinds based on their principle: mechanical stimulation techniques, thermal stimulation techniques, and chemical stimulation techniques. Then, different coal seam stimulation techniques were introduced in detail including stimulation mechanism, development history, and challenges. Two indexes were proposed to evaluate the effectiveness of stimulation techniques. Finally, numerous data from the existing literature were collected and compared. The key findings from the review are

(1) Cryogenic liquid nitrogen stimulation technique has the highest total score among the discussed laboratory-scale stimulation technique 
(2) Hydraulic fracturing and gas injection stimulation techniques have the highest total score among key field-scale stimulation techniques

(3) Considering the time required for each stimulation method to take effect, high-voltage electric fracturing maybe has a higher potential in the future

At present, hydraulic stimulation techniques appear to be most effective, but it may have negative environmental impact due to a large amount of water usage and possible contamination of the precious groundwater. Looking forward, it seems the waterless stimulation methods, e.g., cryogenic liquid nitrogen and high-voltage electric fracturing, are more desirable and thus have greater social and environmental benefits for further development, though they are likely to be the most economical options.

It worth mentioning that despite cryogenic liquid nitrogen and high-voltage electric fracturing offer an important alternative due to its waterless and chemical-free nature, the long-term effectiveness is still unknown. Without proper proppants to support the new fractures, it is highly likely that the fractures can close very rapidly. Any further studies to understand this aspect is really useful.

Both the cryogenic liquid nitrogen and high-voltage fracturing method are not still widely applied on the field, so there is an immediate need to (i) conduct a comprehensive economic comparison between the two techniques, and (ii) to develop reliable equipment and implementation methods for field trial.

\section{Conflicts of Interest}

The authors declared that they have no conflicts of interest to this work.

\section{Acknowledgments}

We would like to thank the reviewers and editors for their valuable comments.

\section{References}

[1] International Energy Agency, Market Report Series: Gas 2019, 2019.

[2] T. A. Moore, "Coalbed methane: a review," International Journal of Coal Geology, vol. 101, pp. 36-81, 2012.

[3] A. D. Alexeev, T. A. Vasilenko, and E. V. Ulyanova, "Closed porosity in fossil coals," Fuel, vol. 78, no. 6, pp. 635-638, 1999.

[4] K. H. S. M. Sampath, M. S. A. Perera, P. G. Ranjith, and S. K. Matthai, " $\mathrm{CO}_{2}$ interaction induced mechanical characteristics alterations in coal: a review," International Journal of Coal Geology, vol. 204, pp. 113-129, 2019.

[5] K. Wang, J. Zang, G. Wang, and A. Zhou, "Anisotropic permeability evolution of coal with effective stress variation and gas sorption: model development and analysis," International Journal of Coal Geology, vol. 130, pp. 53-65, 2014.

[6] Z. Wei and D. Zhang, "Coupled fluid-flow and geomechanics for triple-porosity/dual-permeability modeling of coalbed methane recovery," International Journal of Rock Mechanics \& Mining Sciences, vol. 47, no. 8, pp. 1242-1253, 2010.

[7] J. Zang and K. Wang, "Gas sorption-induced coal swelling kinetics and its effects on coal permeability evolution: model development and analysis," Fuel, vol. 189, pp. 164-177, 2017.

[8] H. Zhang, J. Liu, and D. Elsworth, "How sorption-induced matrix deformation affects gas flow in coal seams: a new FE model," International Journal of Rock Mechanics \& Mining Sciences, vol. 45, no. 8, pp. 1226-1236, 2008.

[9] L. Si, Z. Li, Y. Yang, and R. Gao, "The stage evolution characteristics of gas transport during mine gas extraction: its application in borehole layout for improving gas production," Fuel, vol. 241, pp. 164-175, 2019.

[10] L. Si, Z. Li, Y. Yang et al., "Experimental investigation for pore structure and $\mathrm{CH}_{4}$ release characteristics of coal during pulverization process," Energy \& Fuels, vol. 31, no. 12, pp. 14357-14366, 2017.

[11] L. Si, Z. Li, M. Kizil, Z. Chen, Y. Yang, and S. Ji, “The influence of closed pores on the gas transport and its application in coal mine gas extraction," Fuel, vol. 254, p. 115605, 2019.

[12] Y. Fei, R. L. Johnson, M. Gonzalez, M. Haghighi, and K. Pokalai, "Experimental and numerical investigation into nano-stabilized foams in low permeability reservoir hydraulic fracturing applications," Fuel, vol. 213, pp. 133-143, 2018.

[13] Z. Chen, Z. Pan, J. Liu, L. D. Connell, and D. Elsworth, "Effect of the effective stress coefficient and sorption-induced strain on the evolution of coal permeability: experimental observations," International Journal of Greenhouse Gas Control, vol. 5, no. 5, pp. 1284-1293, 2011.

[14] Z. Pan and L. D. Connell, "Modelling permeability for coal reservoirs: a review of analytical models and testing data," International Journal of Coal Geology, vol. 92, pp. 1-44, 2012.

[15] Z. Pan and L. D. Connell, "Reservoir simulation of free and adsorbed gas production from shale," Journal of Natural Gas Science and Engineering, vol. 22, pp. 359-370, 2015.

[16] N. Yekeen, E. Padmanabhan, and A. K. Idris, "A review of recent advances in foam-based fracturing fluid application in unconventional reservoirs," Journal of Industrial and Engineering Chemistry, vol. 66, pp. 45-71, 2018.

[17] N. Yekeen, E. Padmanabhan, A. K. Idris, and P. S. Chauhan, "Nanoparticles applications for hydraulic fracturing of unconventional reservoirs: a comprehensive review of recent advances and prospects," Journal of Petroleum Science and Engineering, vol. 178, pp. 41-73, 2019.

[18] X. Liu, C. Wu, and K. Zhao, "Feasibility and applicability analysis of $\mathrm{CO}_{2}$-ECBM technology based on $\mathrm{CO}_{2}-\mathrm{H}_{2} \mathrm{O}$-coal interactions," Energy \& Fuels, vol. 31, no. 9, pp. 9268-9274, 2017.

[19] S. R. Grundmann, G. D. Rodvelt, G. A. Dials, and R. E. Allen, "Cryogenic nitrogen as a hydraulic fracturing fluid in the Devonian shale," in SPE Eastern Regional Meeting, p. 6, Pittsburgh, Pennsylvania, 1998.

[20] L. Qin, C. Zhai, J. Xu, S. Liu, C. Zhong, and G. Yu, "Evolution of the pore structure in coal subjected to freeze-thaw using liquid nitrogen to enhance coalbed methane extraction," Journal of Petroleum Science and Engineering, vol. 175, pp. 129-139, 2019.

[21] X. Zhang, B. Lin, Y. Li, C. Zhu, J. Kong, and Y. Li, "Enhancement effect of $\mathrm{NaCl}$ solution on pore structure of coal with high-voltage electrical pulse treatment," Fuel, vol. 235, pp. 744-752, 2019. 
[22] F. Zhou, T. Xia, X. Wang, Y. Zhang, Y. Sun, and J. Liu, "Recent developments in coal mine methane extraction and utilization in China: a review," Journal of Natural Gas Science and Engineering, vol. 31, pp. 437-458, 2016.

[23] V. Valliappan, J. J. C. Remmers, A. Barnhoorn, and D. M. J. Smeulders, "A numerical study on the effect of anisotropy on hydraulic fractures," Rock Mechanics and Rock Engineering, vol. 52, no. 2, pp. 591-609, 2017.

[24] R. J. Davies, S. A. Mathias, J. Moss, S. Hustoft, and L. Newport, "Hydraulic fractures: how far can they go?," Marine and Petroleum Geology, vol. 37, no. 1, pp. 1-6, 2012.

[25] D. U. Chun-Zhi, X. B. Mao, X. X. Miao, and W. Peng, "Effect of ground stress on hydraulic fracturing of methane well," Journal of China University of Mining \& Technology, vol. 18, no. 2, pp. 204-209, 2008.

[26] W. T. Stringfellow, J. K. Domen, M. K. Camarillo, W. L. Sandelin, and S. Borglin, "Physical, chemical, and biological characteristics of compounds used in hydraulic fracturing," Journal of Hazardous Materials, vol. 275, pp. 37-54, 2014.

[27] N. Guanhua, D. Kai, L. Shang, and S. Qian, "Gas desorption characteristics effected by the pulsating hydraulic fracturing in coal," Fuel, vol. 236, pp. 190-200, 2019.

[28] Q. Li, B. Lin, and C. Zhai, "The effect of pulse frequency on the fracture extension during hydraulic fracturing," Journal of Natural Gas Science and Engineering, vol. 21, pp. 296303, 2014.

[29] B. Q. Lin, L. I. Zi-Wen, C. Zhai, B. I. Qiang, and Y. Y. Wen, "Pressure relief and permeability-increasing technology based on high pressure pulsating hydraulic fracturing and its application," Journal of Mining \& Safety Engineering, vol. 28, no. 3, pp. 452-455, 2011.

[30] A. Keshavarz, A. Badalyan, T. Carageorgos, P. Bedrikovetsky, and R. Johnson, "Stimulation of coal seam permeability by micro-sized graded proppant placement using selective fluid properties," Fuel, vol. 144, pp. 228-236, 2015.

[31] C. Zhai, L. I. Xian-Zhong, and L. I. Quan-Gui, "Research and application of coal seam pulse hydraulic fracturing technology," Journal of China Coal Society, vol. 36, no. 12, pp. 1996-2001, 2011.

[32] L. Li, J. Tan, D. A. Wood et al., "A review of the current status of induced seismicity monitoring for hydraulic fracturing in unconventional tight oil and gas reservoirs," Fuel, vol. 242, pp. 195-210, 2019.

[33] Q. Wang, X. Chen, A. N. Jha, and H. Rogers, "Natural gas from shale formation - the evolution, evidences and challenges of shale gas revolution in United States," Renewable and Sustainable Energy Reviews, vol. 30, pp. 1-28, 2014.

[34] B. Lin, F. Yan, C. Zhu et al., "Cross-borehole hydraulic slotting technique for preventing and controlling coal and gas outbursts during coal roadway excavation," Journal of Natural Gas Science and Engineering, vol. 26, pp. 518525, 2015.

[35] Fushun Research Institute AoCS, "Research on new technology of hydraulic slitting," Safety in Coal Mines, vol. 9, pp. 115, 1982.

[36] C. Shen, B. Lin, C. Sun, Q. Zhang, and Q. Li, "Analysis of the stress-permeability coupling property in water jet slotting coal and its impact on methane drainage," Journal of Petroleum Science and Engineering, vol. 126, pp. 231-241, 2015.

[37] F. Yan, B. Lin, C. Zhu et al., "A novel ECBM extraction technology based on the integration of hydraulic slotting and hydraulic fracturing," Journal of Natural Gas Science and Engineering, vol. 22, pp. 571-579, 2015.

[38] V. Klishin, G. Opruk, and A. Ponizov, "Directional hydraulic fracturing application for reduction of rock heaving intensity in the development opening under conditions of SM Kirov Mine," in Proceedings of the 9th China-Russia Symposium "Coal in the 21st Century: Mining, Intelligent Equipment and Environment Protection", Xuzhou City, China, 2018.

[39] Y. Cheng, Y. Lu, Z. Ge, L. Cheng, J. Zheng, and W. Zhang, "Experimental study on crack propagation control and mechanism analysis of directional hydraulic fracturing," Fuel, vol. 218, pp. 316-324, 2018.

[40] B. Huang, J. Liu, and Q. Zhang, "The reasonable breaking location of overhanging hard roof for directional hydraulic fracturing to control strong strata behaviors of gob-side entry," International Journal of Rock Mechanics and Mining Sciences, vol. 103, pp. 1-11, 2018.

[41] X. Zhao, B. Huang, and Z. Wang, "Experimental investigation on the basic law of directional hydraulic fracturing controlled by dense linear multi-hole drilling," Rock Mechanics and Rock Engineering, vol. 51, no. 6, pp. 1739-1754, 2018.

[42] M. Liu, L. Kong, F. Hao, X. Xin, G. Wei, and Y. Liu, “Application of hydraulic flushing technology in severe outburst coal," Journal of China Coal Society, vol. 30, no. 4, pp. 451454, 2005.

[43] L. Yuan, B. Q. Lin, and W. Yang, "Research progress and development direction of gas control with mine hydraulic technology in China coal mine," Coal Science and Technology, vol. 43, no. 1, pp. 45-49, 2015.

[44] F. Hao, L. Sun, and M. Liu, "Research on boreholes space optimization of hydraulic flushing considering press relief and gas drainage effect," Journal of Mining \& Safety Engineering, vol. 31, no. 5, pp. 756-763, 2014.

[45] D. Xu, Y. Huang, Z. Luo, and X. Yang, "Study and application on pressure releasing and permeability improved technology with hydraulic flushing in floor gateway," Coal Science and Technology, vol. 41, no. 2, pp. 42-48, 2013.

[46] Y. Wang, X. He, E. Wang, and Y. Li, "Research progress and development tendency of the hydraulic technology for increasing the permeability of coal seams," Journal of China Coal Society, vol. 39, no. 10, pp. 1945-1954, 2014

[47] Y. Sun, G. Sun, P. Yan, and Y. Peng, "The development of the electric pulse oil- mining technology," High Voltage Engineering, vol. 28, no. 1, pp. 41-44, 2002.

[48] Y. Wang, "Test and application of electric pulse treatment technology in coal-bed gas," Applied Technology, vol. 9, p. 125, 2011.

[49] Q. Shi, Y. Qin, H. Li et al., "Response of pores in coal to repeated strong impulse waves," Journal of Natural Gas Science and Engineering, vol. 34, pp. 298-304, 2016.

[50] F. Yan, Experimental Study on Pulses Induced Fracturing and Permeability Enhancing of Coal Blocks Based on the Electrical Fragmentation Effect, Doctor. China University of Mining and Technology, 2017.

[51] B. Q. Lin, F. Yan, C. Zhu, C. Guo, and Y. Zhou, "Experimental study on crushing coal by electric and heat in the process of highvoltage breakdown in the air condition," Journal of China Coal Society, vol. 41, no. 1, pp. 94-99, 2016.

[52] K. P. Van der Wielen, R. Pascoe, A. Weh, F. Wall, and G. Rollinson, "The influence of equipment settings and rock 
properties on high voltage breakage," Minerals Engineering, vol. 46-47, pp. 100-111, 2013.

[53] F. Yan, B. Lin, C. Zhu et al., "Using high-voltage electrical pulses to crush coal in an air environment: an experimental study," Powder Technology, vol. 298, pp. 50-56, 2016.

[54] F. Ren, L. Ge, T. E. Rufford, H. Xing, and V. Rudolph, "Permeability enhancement of coal by chemical-free fracturing using high-voltage electrohydraulic discharge," Journal of Natural Gas Science and Engineering, vol. 57, pp. 110, 2018.

[55] O. Maurel, T. Reess, M. Matallah et al., "Electrohydraulic shock wave generation as a means to increase intrinsic permeability of mortar," Cement and Concrete Research, vol. 40 , no. 12, pp. 1631-1638, 2010.

[56] W. Chen, O. Maurel, T. Reess et al., "Experimental study on an alternative oil stimulation technique for tight gas reservoirs based on dynamic shock waves generated by pulsed arc electrohydraulic discharges," Journal of Petroleum Science and Engineering, vol. 88-89, pp. 67-74, 2012.

[57] J. Biela, C. Marxgut, D. Bortis, and J. W. Kolar, "Solid state modulator for plasma channel drilling," IEEE Transactions on Dielectrics and Electrical Insulation, vol. 16, no. 4, pp. 1093-1099, 2009.

[58] F. Yan, B. Lin, C. Zhu et al., "Experimental investigation on anthracite coal fragmentation by high-voltage electrical pulses in the air condition: effect of breakdown voltage," Fuel, vol. 183, pp. 583-592, 2016.

[59] F. Yan, J. Xu, B. Lin, S. Peng, Q. Zou, and X. Zhang, "Changes in pore structure and permeability of anthracite coal before and after high-voltage electrical pulses treatment," Powder Technology, vol. 343, pp. 560-567, 2019.

[60] F. Yan, J. Xu, B. Lin, S. Peng, Q. Zou, and X. Zhang, "Effect of moisture content on structural evolution characteristics of bituminous coal subjected to high-voltage electrical pulses," Fuel, vol. 241, pp. 571-578, 2019.

[61] X. Zhang, B. Lin, C. Zhu, Y. Wang, C. Guo, and J. Kong, "Improvement of the electrical disintegration of coal sample with different concentrations of $\mathrm{NaCl}$ solution," Fuel, vol. 222, pp. 695-704, 2018.

[62] W. Pu and Y. Bi, "Permeability improvement gas drainage technology with deep borehole accumulated energy hydraulic blasting of low permeability seam," Coal Science and Technology, vol. 42, no. 5, pp. 37-40, 2014.

[63] J. Liu, Z. Liu, K. Gao, Y. Ma, Z. Li, and L. Guo, "Experimental study and application of directional focused energy blasting in deep boreholes," Chinese Journal of Rock Mechanics and Engineering, vol. 33, no. 12, pp. 2490-2496, 2014.

[64] H. Chen, Z. Wang, X. Chen, X. Chen, and L. Wang, "Increasing permeability of coal seams using the phase energy of liquid carbon dioxide," Journal of CO2 Utilization, vol. 19, pp. 112-119, 2017.

[65] S. P. Singh, "Non-explosive applications of the PCF concept for underground excavation," Tunnelling and Underground Space Technology, vol. 13, no. 3, pp. 305-311, 1998.

[66] X. Yang, G. Wen, H. Sun et al., "Environmentally friendly techniques for high gas content thick coal seam stimulation-multidischarge CO2 fracturing system," Journal of Natural Gas Science and Engineering, vol. 61, pp. 71-82, 2019.

[67] Y. Han, Mechansim Research on Increase Coal Gas Permeability by Liquid $\mathrm{CO}_{2}$ Phase Transition Fracturing Technique, [M.S. thesis], Henan Polytechnique University, 2014.
[68] Y. Cheng, J. Fu, and Q. Yu, "Development of gas extraction technology in coal mine of China," Journal of Mining \& Safety Engineering, vol. 26, no. 2, pp. 127-139, 2009.

[69] M. Qian, X. X. Miao, and J. Xu, "Theoretical study of key stratum in ground control," Journal of China Coal Society, vol. 21, no. 3, pp. 225-230, 1996.

[70] Y. Cheng, Q. Yu, and L. Yuan, "Gas extraction techniques and movement properties of long distance and pressure relief rock mass upon exploited coal seam," Journal of Liaoning Technical University, vol. 22, no. 4, pp. 483-486, 2003.

[71] L. Qin, C. Zhai, S. Liu, and J. Xu, "Mechanical behavior and fracture spatial propagation of coal injected with liquid nitrogen under triaxial stress applied for coalbed methane recovery," Engineering Geology, vol. 233, pp. 1-10, 2018.

[72] C. Zhai, L. Qin, S. Liu, J. Xu, Z. Tang, and S. Wu, "Pore structure in coal: pore evolution after cryogenic freezing with cyclic liquid nitrogen injection and its implication on coalbed methane extraction," Energy \& Fuels, vol. 30, no. 7, pp. 60096020, 2016.

[73] B. W. McDaniel, S. R. Grundmann, W. D. Kendrick, D. R. Wilson, and S. W. Jordan, "Field applications of cryogenic nitrogen as a hydraulic fracturing fluid," in SPE Annual Technical Conference and Exhibition, p. 12, San Antonio, Texas, 1997.

[74] S. Coetzee, H. W. J. P. Neomagus, J. R. Bunt, C. A. Strydom, and $\mathrm{H}$. H. Schobert, "The transient swelling behaviour of large $(-20+16 \mathrm{~mm})$ South African coal particles during low-temperature devolatilisation," Fuel, vol. 136, pp. 79-88, 2014.

[75] M. Cha, X. Yin, T. Kneafsey et al., "Cryogenic fracturing for reservoir stimulation - laboratory studies," Journal of Petroleum Science and Engineering, vol. 124, pp. 436-450, 2014.

[76] Z. Li, H. Xu, and C. Zhang, "Liquid nitrogen gasification fracturing technology for shale gas development," Journal of Petroleum Science and Engineering, vol. 138, pp. 253-256, 2016.

[77] C. Cai, F. Gao, G. Li, Z. Huang, and P. Hou, "Evaluation of coal damage and cracking characteristics due to liquid nitrogen cooling on the basis of the energy evolution laws," Journal of Natural Gas Science and Engineering, vol. 29, pp. 3036,2016

[78] L. Qin, C. Zhai, S. Liu, J. Xu, G. Yu, and Y. Sun, "Changes in the petrophysical properties of coal subjected to liquid nitrogen freeze-thaw - a nuclear magnetic resonance investigation," Fuel, vol. 194, pp. 102-114, 2017.

[79] L. Qin, C. Zhai, S. Liu, J. Xu, S. Wu, and R. Dong, "Fractal dimensions of low rank coal subjected to liquid nitrogen freeze-thaw based on nuclear magnetic resonance applied for coalbed methane recovery," Powder Technology, vol. 325, pp. 11-20, 2018.

[80] C. Cai, G. Li, Z. Huang, S. Tian, Z. Shen, and X. Fu, "Experiment of coal damage due to super-cooling with liquid nitrogen," Journal of Natural Gas Science and Engineering, vol. 22, pp. 42-48, 2015.

[81] C. Jabbour, M. Quintard, H. Bertin, and M. Robin, "Oil recovery by steam injection: three-phase flow effects," Journal of Petroleum Science \& Engineering, vol. 16, no. 1-3, pp. 109130, 1996.

[82] S. Mutyala, C. Fairbridge, J. R. J. Paré, J. M. R. Bélanger, S. Ng, and R. Hawkins, "Microwave applications to oil sands and petroleum: a review," Fuel Processing Technology, vol. 91, no. 2, pp. 127-135, 2010. 
[83] G. C. Sresty, H. Dev, R. H. Snow, and J. E. Bridges, "Recovery of bitumen from tar sand deposits with the radio frequency process," SPE Reservoir Engineering, vol. 1, no. 1, pp. 85-94, 2013.

[84] M. M. Abdulrahman and M. Meribout, "Antenna array design for enhanced oil recovery under oil reservoir constraints with experimental validation," Energy, vol. 66, pp. 868-880, 2014.

[85] M. Bientinesi, L. Petarca, A. Cerutti et al., "A radiofrequency/microwave heating method for thermal heavy oil recovery based on a novel tight-shell conceptual design," Journal of Petroleum Science and Engineering, vol. 107, pp. 18-30, 2013.

[86] H. Li, B. Lin, W. Yang et al., "Experimental study on the petrophysical variation of different rank coals with microwave treatment," International Journal of Coal Geology, vol. 154155, pp. 82-91, 2016.

[87] J.-Z. Liu, J.-F. Zhu, J. Cheng, J.-H. Zhou, and K.-F. Cen, "Pore structure and fractal analysis of Ximeng lignite under microwave irradiation," Fuel, vol. 146, pp. 41-50, 2015.

[88] H. Li, B. Lin, Z. Chen, Y. Hong, and C. Zheng, "Evolution of coal petrophysical properties under microwave irradiation stimulation for different water saturation conditions," Energy \& Fuels, vol. 31, no. 9, pp. 8852-8864, 2017.

[89] G. Li, Y. Meng, and H. Tang, "Clean up water blocking in gas reservoirs by microwave heating: laboratory studies," in nternational Oil \& Gas Conference and Exhibition in China, p. 8, Beijing, China, 2006.

[90] D. Denney, "Cleaning up water blocking in gas reservoirs by microwave heating," Journal of Petroleum Technology, vol. 59, no. 4, pp. 76-81, 2015.

[91] H. Li, B. Lin, W. Yang, Y. Hong, and Z. Wang, "A fully coupled electromagnetic-thermal-mechanical model for coalbed methane extraction with microwave heating," Journal of Natural Gas Science and Engineering, vol. 46, pp. 830-844, 2017.

[92] B. Lin, H. Li, Z. Chen, C. Zheng, Y. Hong, and Z. Wang, "Sensitivity analysis on the microwave heating of coal: a coupled electromagnetic and heat transfer model," Applied Thermal Engineering, vol. 126, pp. 949-962, 2017.

[93] G. T. Feasibility, "Research on the permeability improve by coal acidification," Coal Science and Technology, vol. 42, pp. 137-141, 2014.

[94] Y. Liu, Experiment Recearch on Acidification Reconstruction for Low Permeability Coal Reservior, [M.S. thesis], Henan Polytechnic University, 2016.

[95] L. Wang, B. Chen, and W. Li, "Study on foam fracturing technology for coalbed methane acidification in Lu'an Tunliu," Petrochemical Industry Application, vol. 34, pp. 33-36, 2015.

[96] M. Luo, Study on Composite Permeability Increment Technology by Acid Fracturing in Low Permeability Coal Seam, [Ph.D. thesis], Liaoning Technical University, 2017.

[97] M. C. Potter, "Bacteria as agents in the oxidation of amorphous carbon," Proceedings of the Royal Society of London Series B, Containing Papers of a Biological Character, vol. 80, no. 539, pp. 239-259, 1997.

[98] H. Guo, Z. Gao, D. Xia, X. Yin, J. Jia, and Y. Dou, "Biological methanation of coal in various atmospheres containing CO2," Fuel, vol. 242, pp. 334-342, 2019.

[99] S. H. Harris, R. L. Smith, and C. E. Barker, "Microbial and chemical factors influencing methane production in labora- tory incubations of low-rank subsurface coals," International Journal of Coal Geology, vol. 76, no. 1-2, pp. 46-51, 2008.

[100] M. Faiz, L. Stalker, N. Sherwood et al., "Bio-enhancement of coal bed methane resources in the southern Sydney basin," The APPEA Journal, vol. 43, no. 1, pp. 595-610, 2003.

[101] H. Guo, J. Ma, S. Zhang, and X. Su, "Experimental research on microbial increasing permeability of coal reservoir and its significance," Jouranl of Pure and Applied Microbiology, vol. 7, no. 1, pp. 335-340, 2013.

[102] S. Reeves, R. Gonzalez, S. Harpalani, and K. Gasem, "Results, status and future activities of the coal-seq consortium," Energy Procedia, vol. 1, no. 1, pp. 1719-1726, 2009.

[103] Z. Pan, J. Ye, F. Zhou, Y. Tan, L. D. Connell, and J. Fan, "CO2 storage in coal to enhance coalbed methane recovery: a review of field experiments in China," International Geology Review, vol. 60, no. 5-6, pp. 754-776, 2017.

[104] R. Scott, T. Anne, P. Larry, and C. Chris, The Allison Unit $\mathrm{CO}_{2}$-ECBM Pilot: A Reservoir Modeling Study, Advanced Resources International (United States), United States, 2003.

[105] R. Scott and O. Anne, The Tiffany Unit $N_{2}$ ECBM Pilot: A Reservoir Modeling Study, Advanced Resources International, Incorporated, United States, 2004.

[106] Y. Sun, Y. Zhao, and L. Yuan, "CO2-ECBM in coal nanostructure: modelling and simulation," Journal of Natural Gas Science and Engineering, vol. 54, pp. 202-215, 2018.

[107] D. J. Black, "Cyclic inert gas injection - an alternative approach to stimulate gas drainage from tight coal zones," in 13th Coal Operators' Conference, pp. 291-298, University of Wollongong, Australia, 2013.

[108] S. J. Friedmann, "Geological carbon dioxide sequestration," Elements, vol. 3, no. 3, pp. 179-184, 2007.

[109] D. C. M. White, B. R. Strazisar, E. J. Granite, J. S. Hoffman, and H. W. Pennline, "Critical review: separation and capture of $\mathrm{CO} 2$ from large stationary sources and sequestration in geological formations - coalbeds and deep saline aquifers," Journal of the Air \& Waste Management Association (Air \& Waste M 2003), vol. 53, no. 6, pp. 643-644, 2003.

[110] C. M. White, D. H. Smith, K. L. Jones et al., "Sequestration of carbon dioxide in coal with enhanced coalbed methane RecoveryA Review†," Energy \& Fuels, vol. 19, no. 3, pp. 659-724, 2005.

[111] Y. Zhang, M. Lebedev, M. Sarmadivaleh, A. Barifcani, and S. Iglauer, "Swelling-induced changes in coal microstructure due to supercritical CO2injection," Geophysical Research Letters, vol. 43, no. 17, pp. 9077-9083, 2016.

[112] J. Lin, T. Ren, G. Wang, and J. Nemcik, "Simulation investigation of N2-injection enhanced gas drainage: model development and identification of critical parameters," Journal of Natural Gas Science and Engineering, vol. 55, pp. 30-41, 2018.

[113] L. D. Connell, R. Sander, M. Camilleri, D. Heryanto, Z. Pan, and N. Lupton, "Nitrogen enhanced drainage of CO 2 rich coal seams for mining," International Journal of Mining Science and Technology, vol. 27, no. 5, pp. 755-761, 2017.

[114] J. Lin, T. Ren, G. Wang, P. Booth, and J. Nemcik, "Experimental investigation of $\mathrm{N} 2$ injection to enhance gas drainage in CO2-rich low permeable seam," Fuel, vol. 215, pp. 665674, 2018.

[115] S. Shimada, H. Li, Y. Oshima, and K. Adachi, "Displacement behavior of $\mathrm{CH}_{4}$ adsorbed on coals by injecting pure $\mathrm{CO}_{2}, \mathrm{~N}_{2}$, 
and $\mathrm{CO}_{2}-\mathrm{N}_{2}$ mixture," Environmental Geology, vol. 49, no. 1, pp. 44-52, 2005.

[116] Y. Zhou, Z. Li, R. Zhang et al., "CO2 injection in coal: advantages and influences of temperature and pressure," Fuel, vol. 236, pp. 493-500, 2019.

[117] H. Fang, S. Sang, and S. Liu, "Establishment of dynamic permeability model of coal reservoir and its numerical simulation during the CO2-ECBM process," Journal of Petroleum Science and Engineering, vol. 179, pp. 885-898, 2019.

[118] X. Zhang and P. G. Ranjith, "Experimental investigation of effects of $\mathrm{CO}_{2}$ injection on enhanced methane recovery in coal seam reservoirs," Journal of CO2 Utilization, vol. 33, pp. 394-404, 2019.

[119] X. G. Zhang, P. G. Ranjith, A. S. Ranathunga, and D. Y. Li, "Variation of mechanical properties of bituminous coal under $\mathrm{CO}_{2}$ and $\mathrm{H}_{2} \mathrm{O}$ saturation," Journal of Natural Gas Science and Engineering, vol. 61, pp. 158-168, 2019.

[120] J. Lin, T. Ren, G. Wang, P. Booth, and J. Nemcik, "Experimental study of the adsorption-induced coal matrix swelling and its impact on ECBM," Journal of Earth Science, vol. 28, no. 5, pp. 917-925, 2017.

[121] Y. Mu, Y. Fan, J. Wang, and N. Fan, "Numerical study on the injection of heated $\mathrm{CO}_{2}$ to enhance $\mathrm{CH}_{4}$ recovery in waterbearing coal reservoirs," Energy Sources, Part A: Recovery, Utilization, and Environmental Effects, pp. 1-19, 2019.

[122] C. Fan, D. Elsworth, S. Li, L. Zhou, Z. Yang, and Y. Song, "Thermo-hydro-mechanical-chemical couplings controlling $\mathrm{CH} 4$ production and $\mathrm{CO} 2$ sequestration in enhanced coalbed methane recovery," Energy, vol. 173, pp. 1054-1077, 2019.

[123] S. Wu, Experimental Study on the Effect of Freeze-Thaw Action on Coal Damage and Gas Dispersion, [M.S. thesis], China University of Mining and Technology, 2017.

[124] H. Y-d, B.-q. Lin, C.-j. Zhu, and H. Li, "Effect of microwave irradiation on petrophysical characterization of coals," Applied Thermal Engineering, vol. 102, pp. 1109-1125, 2016.

[125] Y. Hong, Temperature Rise Characteristics and Pore Structure Modification of Coals during Microwave Irradiation, [Ph.D. thesis], China University of Mining and Technology, 2017.

[126] S. Dai, Experimental Study on Gas Adsorption Modification of Coal Particles after Microwave Irradition, [M.S. thesis], Henan Polytechnic University, 2015.

[127] H. Li, B. Lin, Y. Hong et al., "Effect of microwave irradiation on pore and fracture evolution of coal," Journal of China University of Mining \& Technology, vol. 46, no. 6, pp. 1194-1201, 2017.

[128] F. Yan, B. Lin, J. Xu, Y. Wang, X. Zhang, and S. Peng, "Structural evolution characteristics of middle-high rank coal samples subjected to high-voltage electrical pulse," Energy \& Fuels, vol. 32, no. 3, pp. 3263-3271, 2018.

[129] H. Li, Behavior and Mechnism of Fracturing and EnhancedPermeability of Coals with Electric Pulse Stress Waves, [Ph.D. thesis], China University of Mining and Technology, 2015.

[130] S. Li, M. Luo, C. Fan, H. Bi, and Y. Ren, "Quantitative characterization of the effect of acidification in coals by NMR and low-temperature nitrogen adsorption," Journal of China Coal Society, vol. 42, no. 7, pp. 1748-1756, 2017.

[131] H. Guo, Y. Luo, J. Ma, D. Xia, C. Ji, and X. Su, "Analysis of mechanism and permeability enhancing effect via microbial treatment on different-rank coals," Journal of China Coal Society, vol. 39, no. 9, pp. 1886-1891, 2014.
[132] C. Wang, Y. Bao, and Y. Ju, "Micropore structure evolution of organic matters in coal measures due to bioconversion using FE-SEM, HIP and $\mathrm{N}_{2}$ adsorption experiments," Earth Science, vol. 45, pp. 1-14, 2018.

[133] X. Zhang, J. Yu, and J. Liu, "Application of directional fracturing increased permeability technology in no. II-1 coal seam," Journal of North China Institute of Science and Technology, vol. 8, no. 3, pp. 35-38, 2011.

[134] X. Li, The Mechnism and Technology of Permeability Enhancements in Coal Seam Based on High Pressure Pulsating Hydraulic Fracturing, [Ph.D. thesis], China University of Mining and Technology, 2013.

[135] J. Ma, Study on Soft Coal Seam Drilling Pumps in Parallel Hydraulic Fracturing Technology, [M.S. thesis], China University of Mining and Technology, 2017.

[136] G. Ni, Microscopic Kinetics Characteristics of Methane under Pulasting Hydraulic Fracturing and Mechanism of Liquid Retention Effect, [Ph.D. thesis], China University of Mining and Technology, 2015.

[137] J. Zhang, Permeability in Improvement in Gas Extraction Hydraulic Fracturing with Borehole Crossing the Rock and Coal Seam in Xinjing Coal Mine, [M.S. thesis], China University of Mining and Technology, 2017.

[138] S. Xue, Study on Permeability Effect of Hydraulic Fracturing in Low Permeability Coal Seam, [m.S. thesis], China University of Mining and Technology, 2012.

[139] Y. Wang, Study on Permeability-Increasing Technology Combining $3 D$ Swirling Water Jet with Hydraulic Fracturing, [Ph.D. thesis], China University of Mining and Technology, 2015.

[140] X. Chen, "Permeability improvement technology of directional hydraulic fracturing in low permeability coalseam," Journal of Liaoning Technical University(Natural Science), vol. 35, no. 2, pp. 124-128, 2016.

[141] C. Fan, The Key Technology and Application for Pressure Relief and Permeability Increasing by Hydraulic Flushing in "Three Soft" Coal Seam, [M.S. thesis], Henan Polytechnic University, 2015.

[142] Z. Cao, Research on Multi-Field Coupling Effect on Hydraulic Punching in Close Distance Coal Seam and Evaluation of Pressure Release Gas Extraction Effect, [Ph.D. thesis], China University of Mining and Technology, 2018.

[143] H. Xiao, The Applicaiton of in-Seam Borehole Hydraulic Flushing Technology in Enhancing the Gas Extraction in the Xinjing Coal Mine, [M.S. thesis], China University of Mining and Technology, 2017.

[144] H. Yang, Study on the Application of Hydraulic Punching and Pressure Relief and Permeability Increasing Thechnology for High Gas Seam in Liang Bei Coal Mine, [M.S. thesis], China University of Mining and Technology, 2018.

[145] M. Liu, K. Cui, Y. Liu, Q. Deng, and Z. Liu, “Analysis on outburst prevention mechanism of borehole hydraulic flushing measures for deep and low permeability seam," Coal Science and Technology, vol. 40, no. 2, pp. 45-48, 2012.

[146] H. M. Bureau, "A new method for improving the gas driange efficiency: hydraulic cutting in borehole," Safety in Coal Mines, vol. 2, pp. 5-14, 1987.

[147] Y. Zhang, "Improvement of gas drainage efficiency of lowpermeability coal seams using ultra-high pressure hydraulic cutting technique," IOP Conference Series: Materials Science and Engineering, vol. 472, article 012084, 2019. 
[148] Q. Zou, Weakening-Relaxation Mechanism and Fluid-Solid Coupling Property of Low-Permeability Coal Subjected to Hydraulic Slotting, [Ph.D. thesis], China University of Mining and Technology, 2016.

[149] H. Liu, Z. Sun, and M. Tang, "Study on the technology of hydraulic slotting with ultra-high pressure for enhanced gas drainage," Journal of Anhui Jianzhu University, vol. 25, no. 6, pp. 41-44, 2017.

[150] Y. Song, M. Wang, A. Wang, and L. Du, "Study on enhancing gas permeability by ultra-high pressure waterjet cutting coal seam," China Energy and Environmental Protection, vol. 39, no. 4, pp. 44-47, 2017.

[151] H. Wu, The Theory and Technology Study on Pressure Relief Permeability Enhancements of the Caol Seam with High Concentration of Gas and Low Permeability, [Ph.D. thesis], China University of Mining and Technology, 2009.

[152] Y. Han and D. Song, "Experimental study on permeability improvement technology by cutting seam using high pressure water jet in coal seam with low permeability," Journal of Safety Science and Technology, vol. 10, no. 12, pp. 35-39, 2014.

[153] Z. Wang, Y. Song, B. Shi, and A. Wang, "Study on low permeability coal seam hydraulic cutting seam permeability improvement technology of Changcun mine," Coal and Chemical Industry, vol. 38, no. 12, pp. 12-14, 2015.

[154] W. Jiang, Research on Theory of Slotting and Enhancing Permeability by High Pressure Rotational Jetting in Low Permeability Coal Seam and its Application, [Ph.D thesis], China University of Mining and Technology, 2009.

[155] Z. Ti, F. Zhang, J. Pan, X. Ma, and Z. Shang, "Permeability enhancement of deep hole pre-splitting blasting in the low permeability coal seam of the Nanting coal mine," PLoS one, vol. 13, no. 6, article e0199835, 2018.

[156] Y. Lou, Applicaiton of study of deep borehole loose blasting

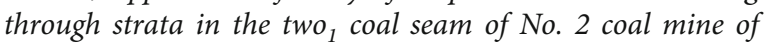
Zhaogu, [M.S. thesis], Anhui University of Science \& Technology, 2016.

[157] H. Wang, Study of Mechanism on Enhancing Permeability of High Stressed and Low Permeable Coal Seam in Deep Mining by Pre-Splitting Controlled Blasting Technology, [Ph.D. thesis], Institute of Engineering Mehanics, China Earthquake Administration, 2012.

[158] Z. Wang, D. Zhou, H. Li, and L. Zhao, "Research on secondary fracturing technology by phase transformation of liquid $\mathrm{CO}_{2}$," Journal of Henan Polytechnic University(Natural Science), vol. 35, no. 5, pp. 597-600, 2016.

[159] Z. Wang, X. Sun, T. Lu, and Y. Han, "Experimental research on strengthening gas drainage effect with fracturing technique by liquid $\mathrm{CO}_{2}$ phase transition," Journal of Henan Polytechnic University (Natural Science), vol. 34, no. 1, pp. 1-5, 2015.

[160] X. Sun, Research on Strengthening Gas Pre-Drainage Effect with the Fracturing Technique by Liquid $\mathrm{CO}_{2}$ Phase Transition in Layer through Boring, [M.S. thesis], Henan Polytechnic University, 2014.

[161] Z. Bai, "Liquid $\mathrm{CO}_{2}$ circulation of blasting for increasing permeability of coal seam," Coal Technology, vol. 35, no. 4, pp. 184-187, 2016. 